\title{
The Effect of Life Skills Training on Parental Stress of Women Health Volunteers with Children Aged Less than Seven Years
}

\author{
Fatemeh Shakeri ${ }^{1}$, Mehrnoosh Inanloo $^{2}$, Hamid Haghani ${ }^{3}$
}

\begin{abstract}
Background \& Aims: One of the most important events in life is accepting the parental role which causes a lot of stress regarding its responsibilities and expectations. Parental stress is caused by a perceived mismatch between parental responsibilities and personal resources such as some of the child characteristics including poor response, behavioral problems, child adjustment, as well as specific parental characteristics such as flexibility, anxiety, and life skills deficits in interaction with the child characteristics. High levels of parental stress disrupt parent-child interactions and even, low levels of parental stress and parental inefficiency are linearly related, making parents, especially mothers, more captious, stricter, and more sensitive, which in turn leads to behavioral problems and emotional development disorders in their children. Since the emotional and psychological state of the parents is influential during the childhood of their children, there is a need for appropriate methods to overcome this stress. Numerous studies have shown that teaching life skills to parents is one of the most effective and efficient therapeutic methods with a positive and significant effect on reducing parental stress and children's stress, and the most appropriate way to develop skills and change behavior is to hold life skills workshops. Accordingly, this study aimed to determine the effect of life skills training on parental stress in women health volunteers with children under 7 years old in Abhar city.

Materials \& Methods: This was a quasi-experimental study with a control-experimental group that investigated the effect of life skills on the parental stress of women health volunteers with children under 7 years old in Abhar in 2019. For this purpose, 60 women health volunteers with children under 7 years old were selected through convenience sampling method from two comprehensive health care centers in Abhar. Having introduced the research objectives, volunteers who met the inclusion criteria were selected and completed the consent form. The personal information form asked about the age of the volunteers, their husbands and children, the number of children, the occupation and income of their husbands, their education level, their husbands' education level, and the duration of their cooperation with the relevant centers. The Parenting Stress Index- Short Form (SF-PSI), with 36 questions on a 5-point Likert scale with a score of 1-5, and three sets of 12 questions about three subscales of parental distress, parent-child dysfunctional interactions, and difficult child were given to them. A total score greater than 90 indicates high parental stress. The experimental group participants were divided into two groups of 15 to undergo treatment for 5 sessions. The treatment included group life skills training programs such as selfawareness, self-esteem, and self-confidence skills, effective communication skills and bravery, emotion and anger control skills, stress management skills, and problem-solving skills. Content validity of the educational materials was approved by psychiatric nursing professors. The educational materials were presented in the form of questions and answers, lectures, role-play, and practical and home exercises for three weeks, and two 105 minute sessions per week. However, the control group did not receive any treatment and in the end, both groups took the post-test five weeks after the intervention. The educational package was delivered to both groups. This study is extracted from a research project approved by Iran University of Medical Sciences and the ethical policy of the university

\footnotetext{
${ }^{1}$. Department of Community-oriented virtual education, School of Nursing and Midwifery, Iran University of Medical Sciences, Tehran, Iran

${ }^{2}$. Department of Child and Psychiatric Nursing, School of Nursing and Midwifery, Iran University of Medical Sciences, Tehran, Iran (Corresponding author) Tel: 02143651180 Email: Inanlou.m@Iums.ac.ir
}

3. Department of Biostatistics, School of Health, Iran University of Medical Sciences, Tehran, Iran
\end{abstract}


was observed during the study. Descriptive and inferential statistics were first calculated and then the hypotheses were analyzed using the statistical methods of independent t-test, ANCOVA, and Mann-Whitney test at a significant level of $\mathrm{P} \leq 0.01$. Data were analyzed using SPSS software version 16 and statistical tests.

Results: There was no significant difference between the two groups in terms of age, their education level, their husbands' education level, income, the number of children, their age and sex, and duration of cooperation. The mean scores of parental stress in the pre-test were $109.13 \pm 3.1$ and $114.3 \pm 16.39$ for the control and the experimental group respectively. The mean scores of parental stress in the post-test (five weeks after the intervention) were $97.6 \pm 14.52$ and $89.8 \pm 17.83$ for the control and experimental groups respectively, indicating a statistically significant difference between the two groups $(\mathrm{P} \leq 0.001)$. The results showed that life skills training reduced parental stress in the experimental group. The parental anxiety subscale in the experimental group decreased from $40.1 \pm 7.36$ to $28.8 \pm 3.24$. The subscales of the parent-child interaction decreased from $33.5 \pm$ 7.09 to $27.93 \pm 3.88$, while decreasing from $40.7 \pm 5.37$ to $33.3 \pm 1.65$ in the difficult child. After treatment, the mean scores of parental stress and parental anxiety of the experimental group were significantly lower than the control group, indicating less stress of this group compared to the control group $(\mathrm{P}<0.001)$.

Conclusion: The results showed that the life skills training program in women health volunteers reduces the mean scores of parental stress and stress subscales. Therefore, teaching life skills to parents is necessary, and it is recommended that the necessity of life skills training become a culture among the public, and the authorities and managers of health care pay more attention to holding life skills training workshops for parents.

Keywords: Parental Stress, Life Skills, Women Health Volunteers

\section{Conflict of Interest: No}

How to Cite: Shakeri F, Inanloo M, Haghani H. The Effect of Life Skills Training on Parental Stress of Women Health Volunteers with Children Aged Less than Seven Years. Iran Journal of Nursing. 2021; 33(128):84-99.

Received: 16 Nov 2020

Accepted: 17 Feb 2021 


\title{
تأثير آموزش مهارتهاى زندكى بر استرس والدى زنان رابط سلامت داراى كودك زير Y سال
}

\author{
فاطمه شاكرى'، مهرنوش اينانلو'، حميد حقانى
}

\begin{abstract}
جִكيده
زمينه و هدف: يكى از رويدادهاى مهم زندگى يذيرش نقش والدى است كه استرس فراوانى در مقابل مسئوليتها و انتظارات اين نقش وجود دارد.

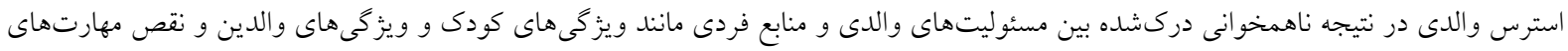

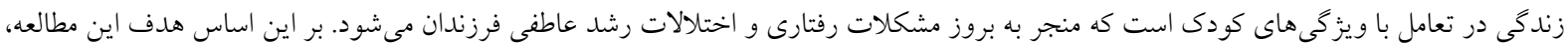

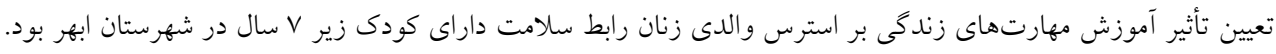

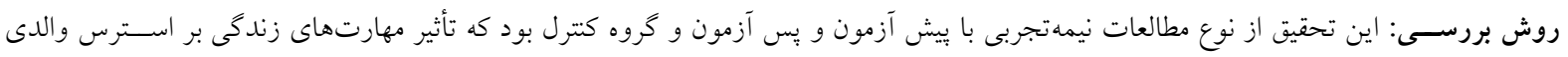

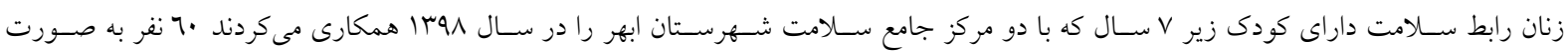

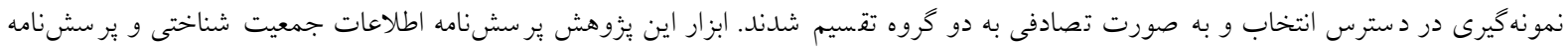

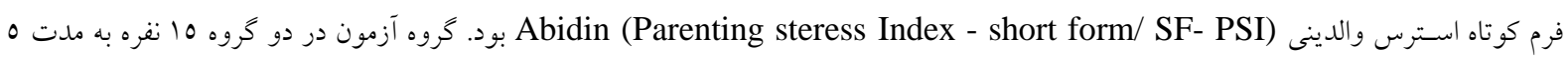

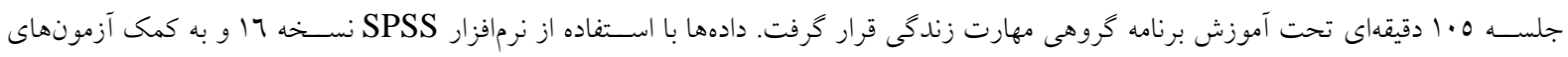
آمارى تى مستقل، تحليل كوواريانس و آزمون من ويتنى تحليل شدند.

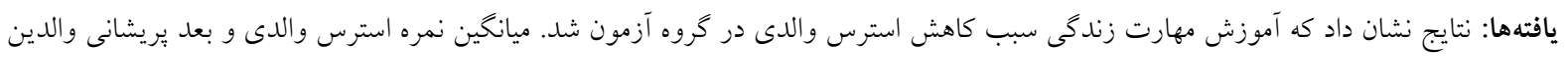

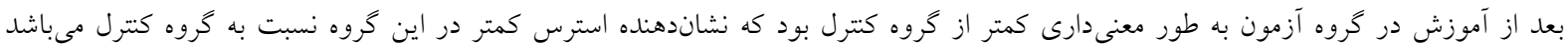

. $(\mathrm{P}<\cdot / \cdots 1)$ نتيجه گيرى كلى: نتايج نشان مىدهد كه برنامه آموزش مهارت زندگى در رابطين سلامت ميانخين استرس والدى و خرده مقياسهاى استرس را كاهش

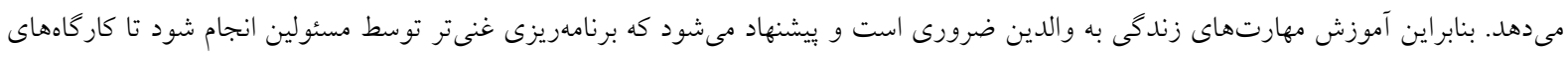

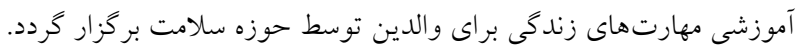

كليد وازهها: استرس والدى، مهارت زندگى، زنان رابط سلامت

تعارض منافع: ندارد

تاريخ دريافت: 99/1/Y

تاريخ بذيرش: 99/11/T9

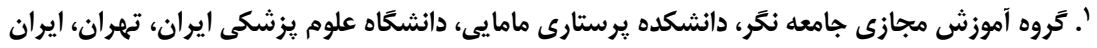

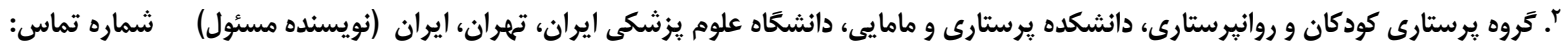

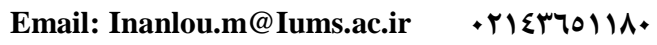
". تَروه آمار زيستى، دانشكده بهداشت، دانشًاه علوم يزشكى ايران، تهران، ايران 


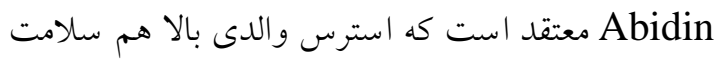
روانى والد و هم سلامت روانى كودى را با خطر مواجه

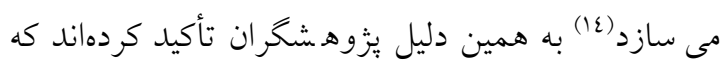
لازم است عوامل استرسزاى گوناگون و روابط بين آنها مشــص كردند و مدلهاى كاملتر و يبيجيدهترى كه بتو انند اثرات عوامل مختلف بر استرس والدى را منعكس

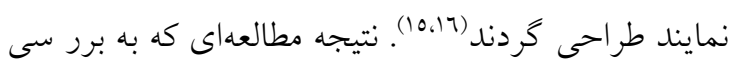

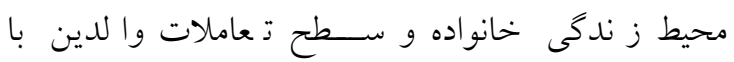

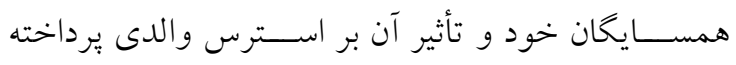
است، نشان مىدهد و الدينى كه سطوح بالاترى از حمايت اجتماعى دارد، سـطوح هيايينتر اسسترس والدى و درنتيجه سطح پايين بى توجهى نسبت به كودكان را دارا هستند (IV).

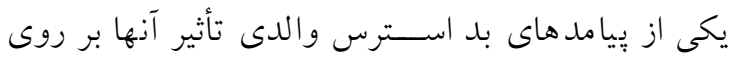

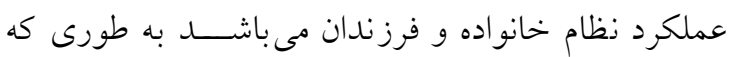

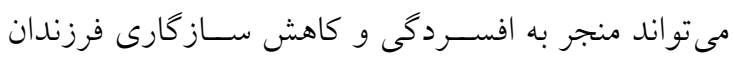

شود

در رابطه با استرس والدى، والدين مىتوانند طيفى از

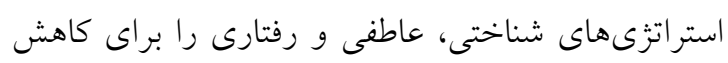

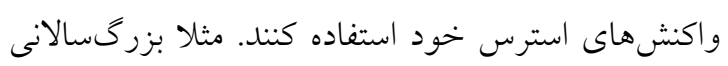

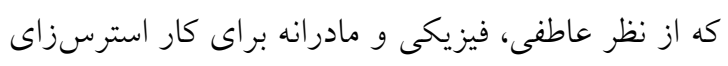

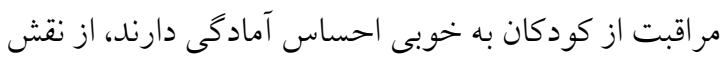

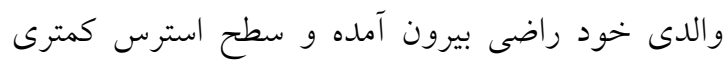
نشان دادند (19). بر اساس مطالعه غريبى و همكاران آموزش مهارتهاى دادئ

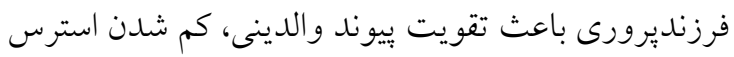

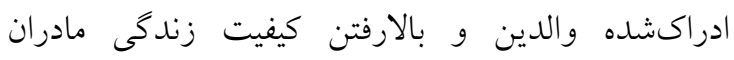

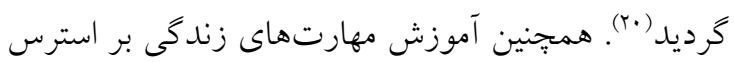

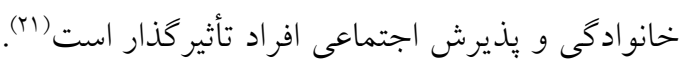
نشان دادند كه بركـزارى يـك Irelan \& Vayzner

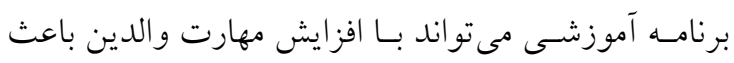
تغيير روابط والد- كودى و كاهش استرس والدى واند آنـان

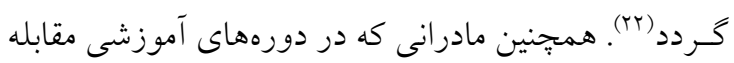

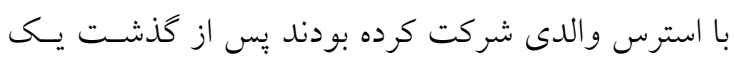

\section{مقدمه}

يرورش فرزند يكى از وظايف جالشبرانكيز والدين است و كاهى عامل ايجاد تنيدگى در خانواده مى شود. والدين اغلب در مورد جّخونكى برخورد صحيح با فرزندان نخرانى هايى دارند، اخر اين نخر انى ها با برخى متغيرهاى ديخر مانند استرس زياد والدين همراه شود؛ به تعامل ناكار آمد والدفرزند منجر شده و موجب كاهش عزتنفس و شكل گيرى خوديندارى منفى والدين و كودكان مىشود (1).

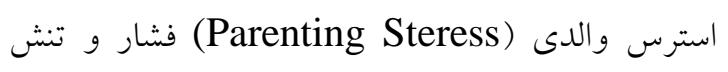
ناشى از تقاضاها، مسئوليت ها و دشوارى هاى مرتبط با نقش

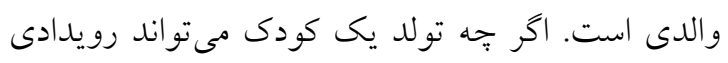

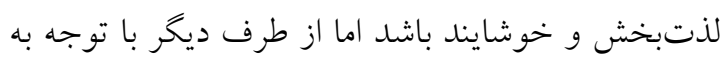

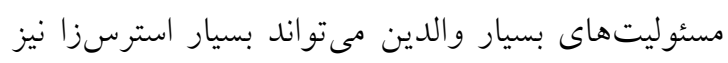

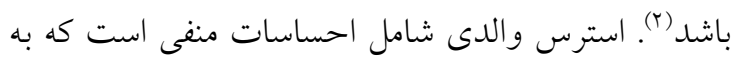
طور خاص از نقش والدين نشأت گرفته است (r).

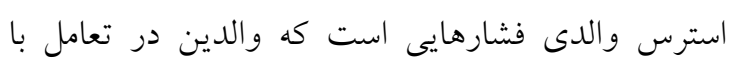

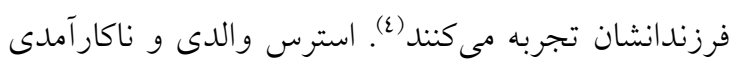

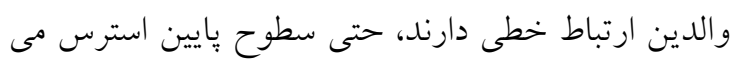

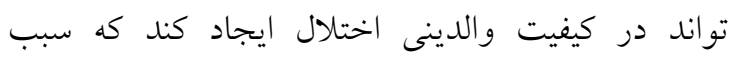

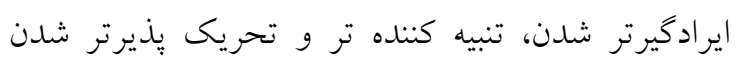

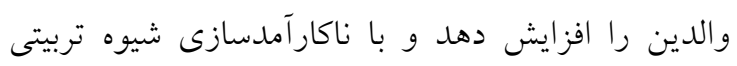

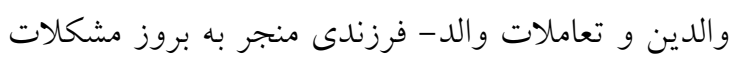

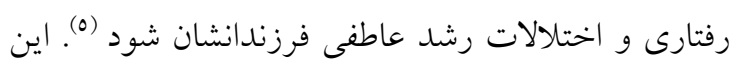

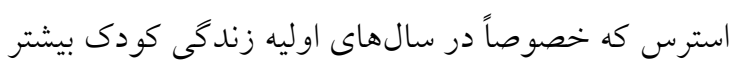

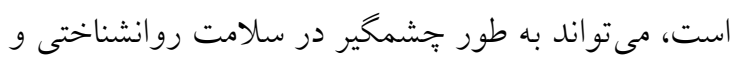

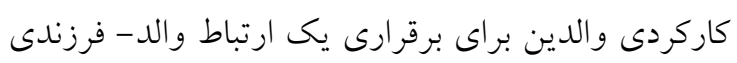
اوليه و نيز در رشد رفتارى و عاطفى فرد اختلال ايجاد

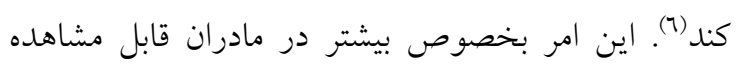

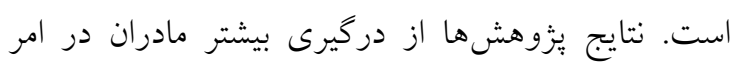

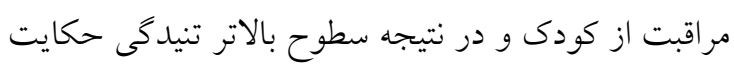

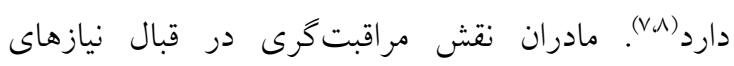

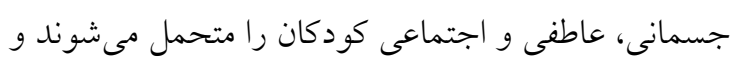
به عبارتى بيشتر وظيفه تربيت فرزندان را به عهله دارند 
1. تنفسى فوقانى ال درصسـ و تغذيه كودك شسيرخوار درصد افزايش يابد (T).

وزارت بهداشت و درمان و آموزش يزشكى بـ بابا انكيزه حل

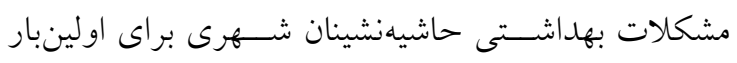
در بايان دهد ·7 اقدام به طراحى و اجراى طرح رابطين

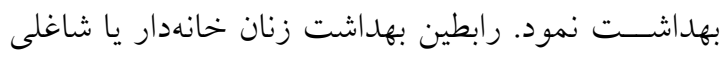

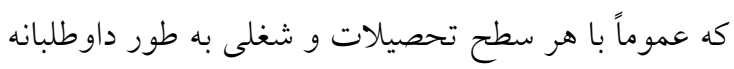

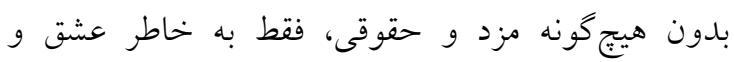
انسانيت و حس مسئوليتيذيرى در برابر جامعه، مانند حلقه ارتباطى بين مسئولان بهداشتى و مردم عمل مى كنند.

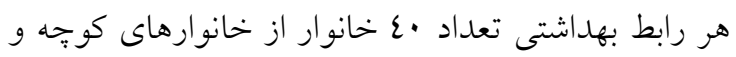
محل سكونت خودش را تحت يوشش قرار مىدهد و ملزم

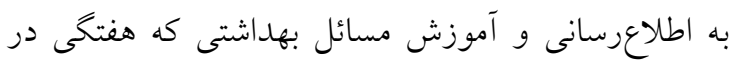

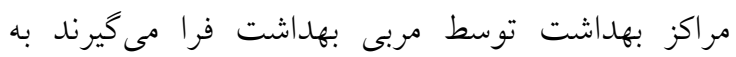

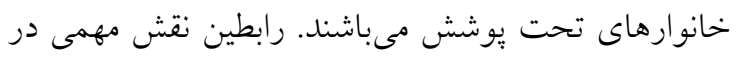

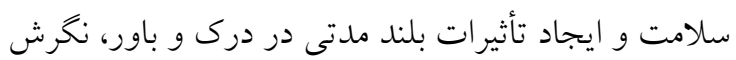

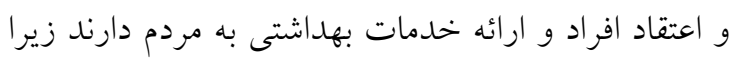

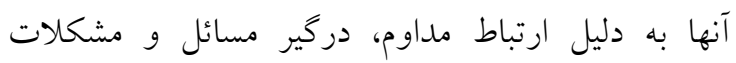

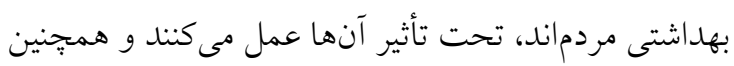

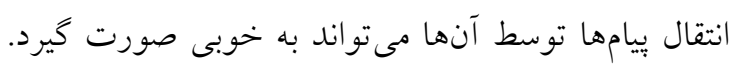
آنها در بسيارى اوقـات به طور غيرمستقيم نيز اثر كذار بوده تونه

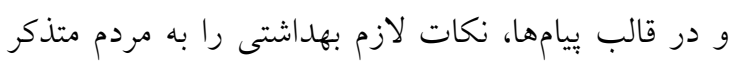

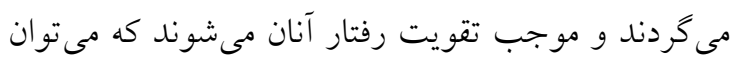

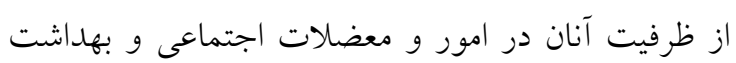
روان نيز بهره برد.

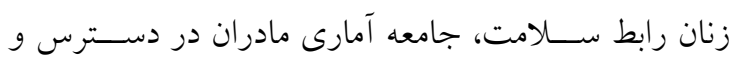

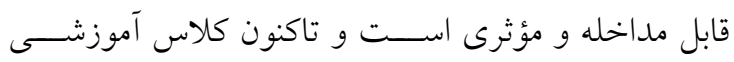
منســـم در خصـــوص مهارتهاى زندكى براى رابطين

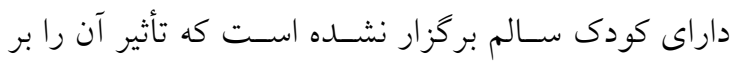

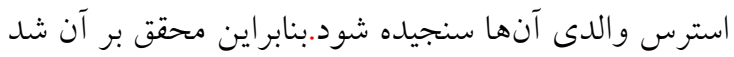

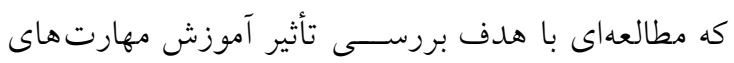

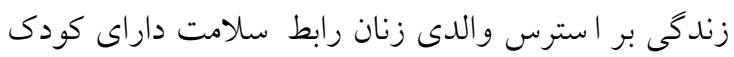

زير V سال را انجام دهد.

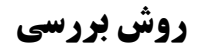

دوره شش سـاله ميـزان اسـترس آنها تا حد نرمال باييين بود2 (rr)

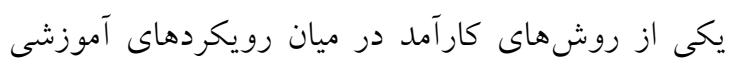

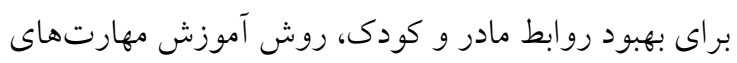

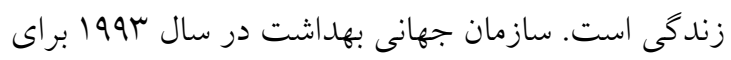

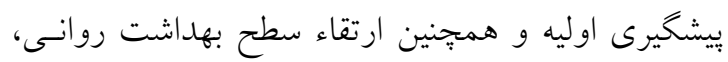

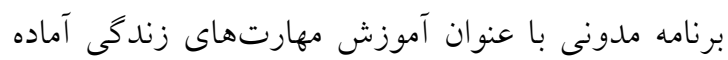

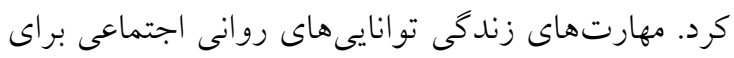

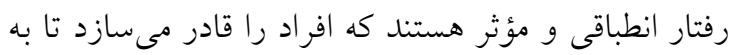

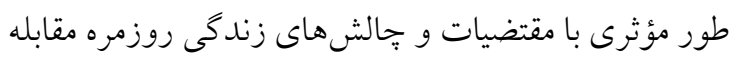

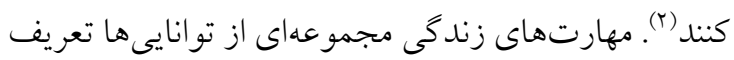
مىشود كه زمينه مقابله مؤثر با فشارهاى روانى و ارائه

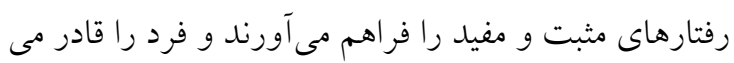
سازند، مسئوليتهاى نقش اجتماعى خود را بيذيرد و بدون لطمه زدن به خود و ديكران با خواستها، انتظارات و مشكلات روزانه به شكل مؤثرى روبرو شود كه شامل دماله

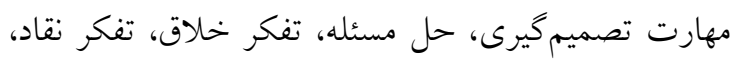

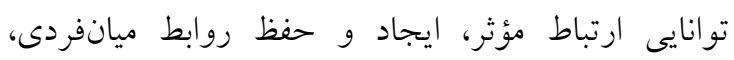
خودآكاهى، همدلى كردن، مهارت مقابله با هيجانها و فشار روانى مىباشد (ع).

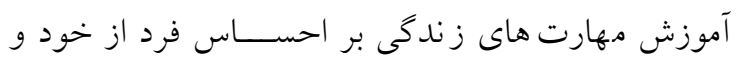

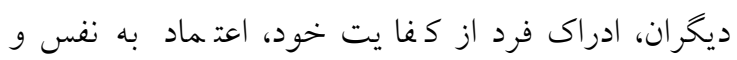

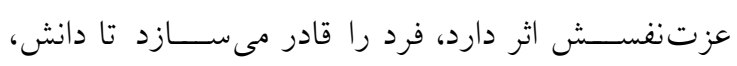

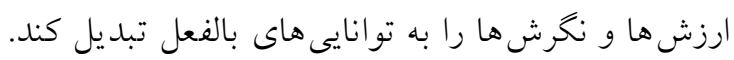

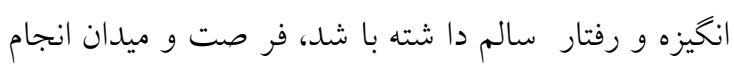

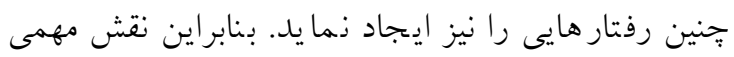
در سلامت روان دارد (ro).

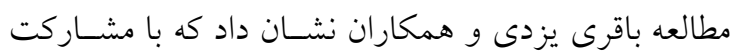

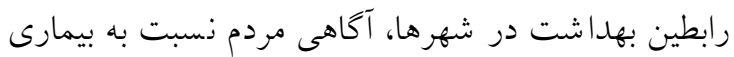
هاى روانى به ميزان Or درصســ و در زمينههاى فاصسـله

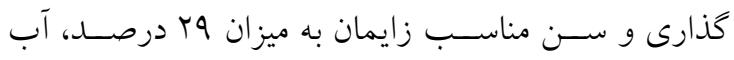

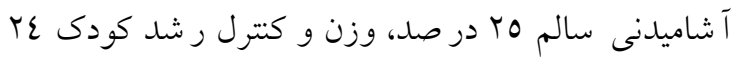

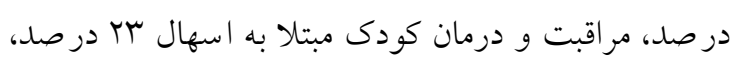
مراقبت و در مان كودى مبتلا به عفو نت هاى دســـاه 
آموزش و تكميل بر سشنامه در ماههاى آبان و آذر يهبا

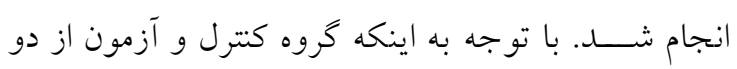

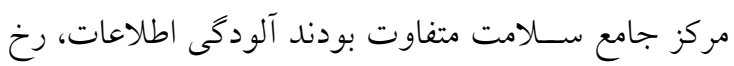

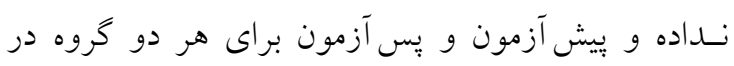

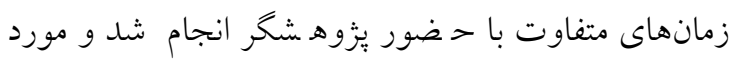

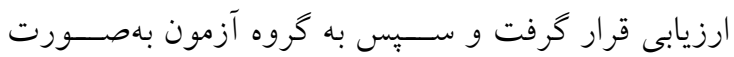
كروهى آموزش داده شد. معيارهاى ورود داشتن حداقل يك سال سابقه همكارى با

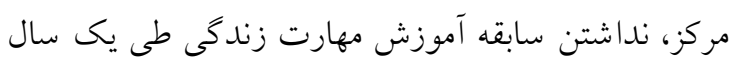

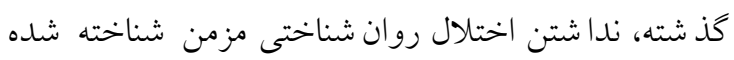

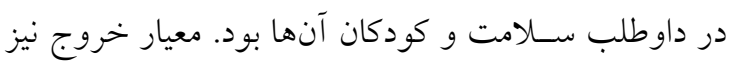

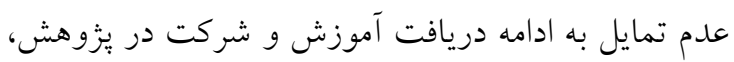

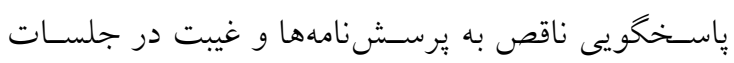
آموزشى بيش از دو جلسه بودي ناسص به برنس

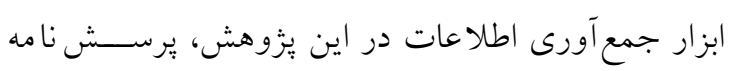
بود. 1- ير سشنامه سؤ الات جمعيتشناختى شامل سؤ الاتى در

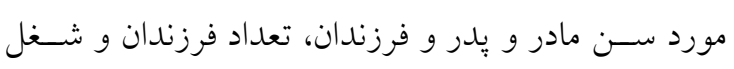

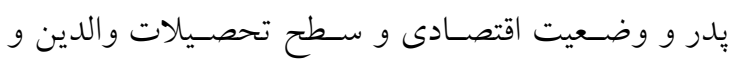
جنس و سن فرزند موردنظر و مدت همكارى بود.

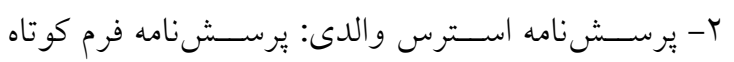
اسـترس والدى (Parenting Stress Scale) در ابتدا

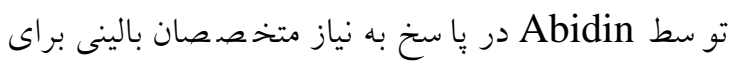

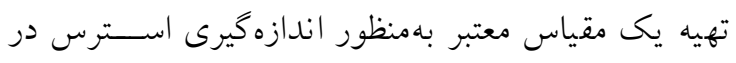
روابط والد-فرزند كه در يكى زمان محددود قابل اجرا با شد، براى سنجش استرس والدين كودكان زير بال وال سال

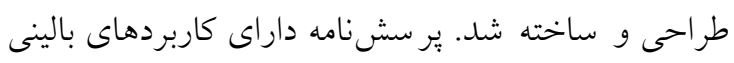

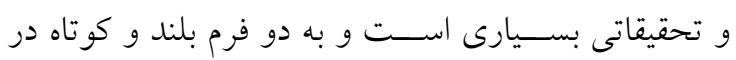

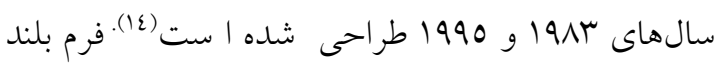
آن با وجود دا شتن ويزّكى هاى روان سنجى قوى، با تعداد

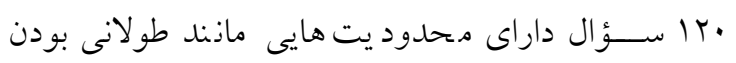

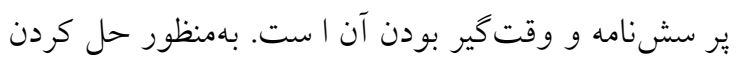

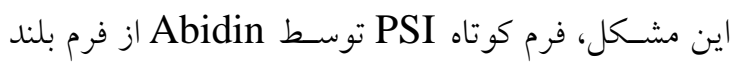

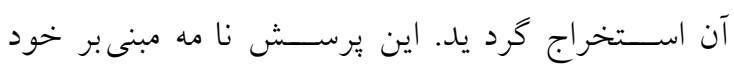

اين مطالعه از نوع مطالعات نيمه تجربى با كروه آزمون-

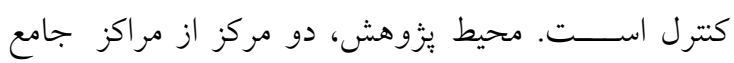

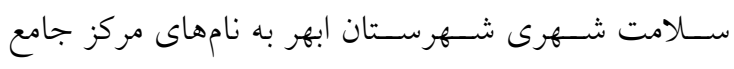

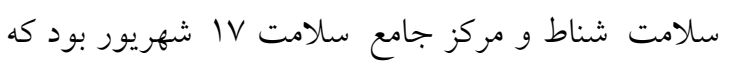
در دو منطقه حاشيه شهر ابهر واقع شدهاند. جمعيتى حدود

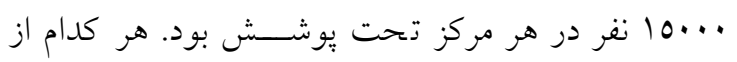

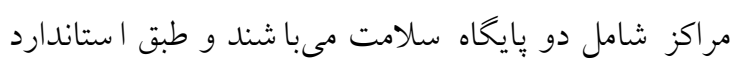

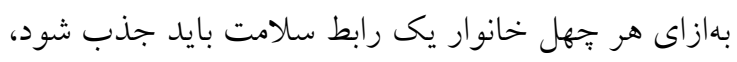

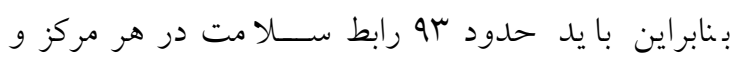

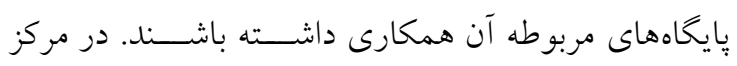

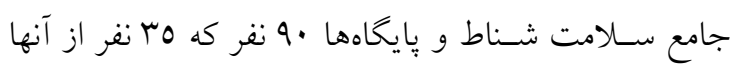

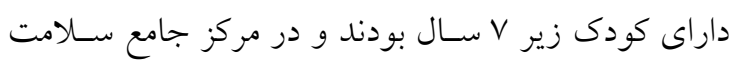
IV

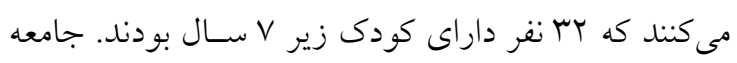

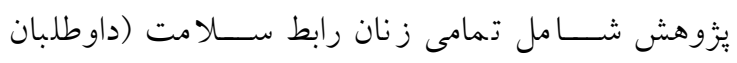

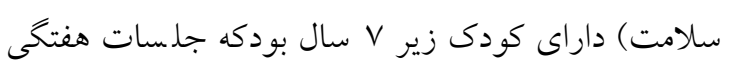

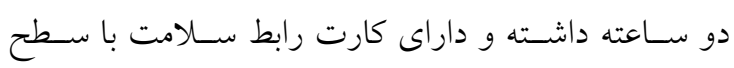

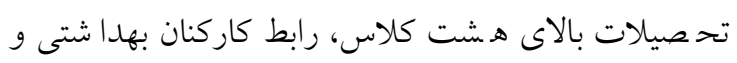
•ع خانوار تحت يوشش خودشان بودند.

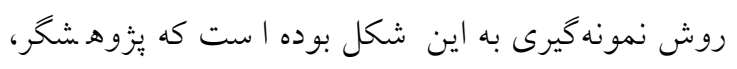

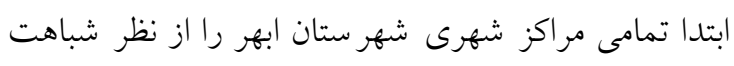

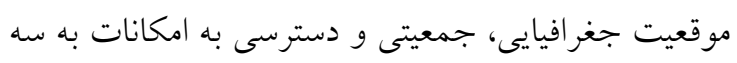
كروه دوتايى تقسيم كرده و به صورت تصادفى ساده دو

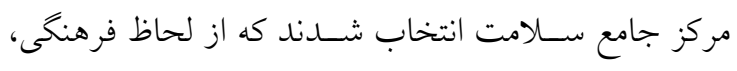

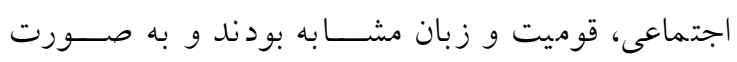

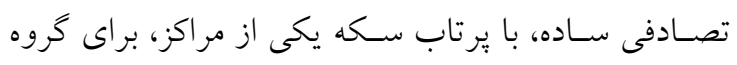

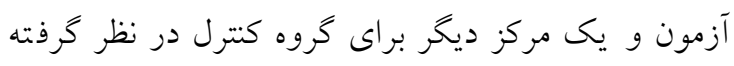

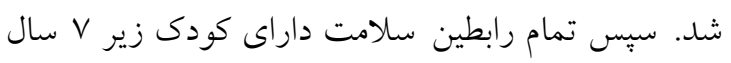

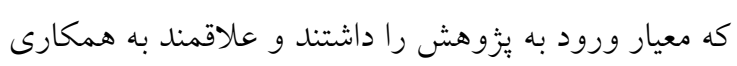

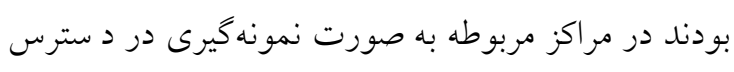

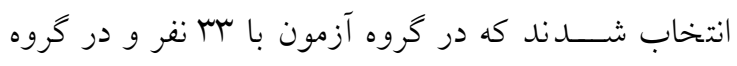

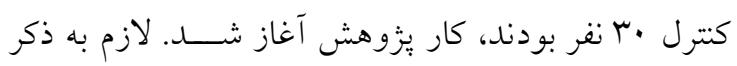

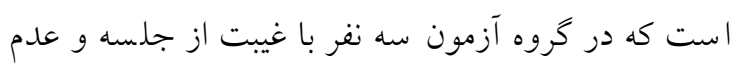
همكارى خارج شدند. 
دانشكده ير ستارى و مامايى دانشخاه علوم يز شكى ايران

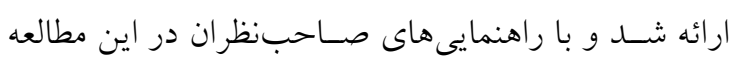
مورد استفاده قرار خرفت. يرسشنامه استرس والدى PSI(SF36) Abidinه معيار

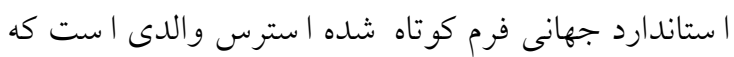

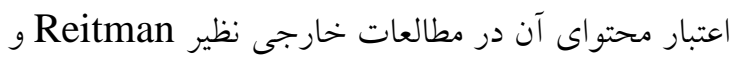

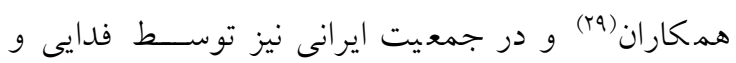

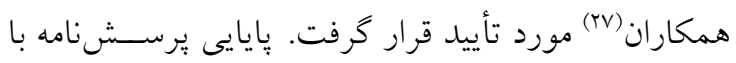
استفاده از ضريب آلفاى كرونباخ ايل/ • محاسبه شد.

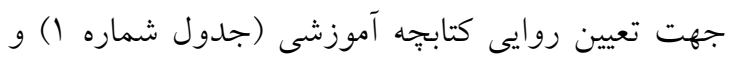
يرسشنامه جمعيتشناختى از روايى محتوى استفاده شد. به اين ترتيب كه يزوهشخر با استفاده از مطالعات كتابخانه

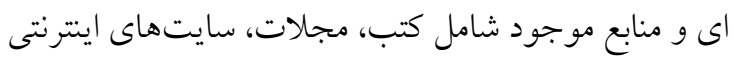

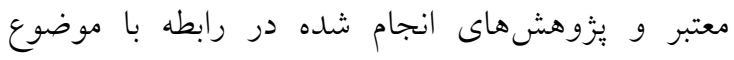

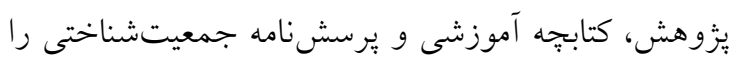

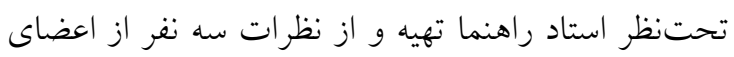
هيئتعلمى متخصص دانشكده يرستارى و مامايى ايران

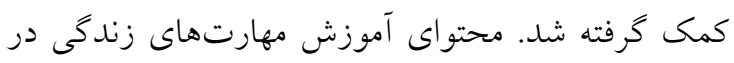
جدول شماره ا مشاهده مى گردد.

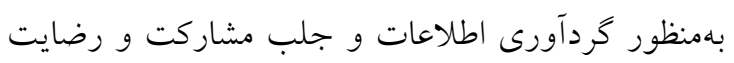
رابطين هماهنكى صورت كرفت و اهداف مطالعه توضيح داده شد و افرادى كه تمايل به شركت در مطالعه داشتند،

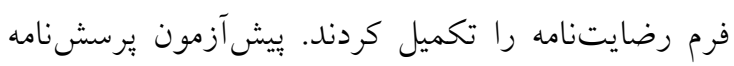

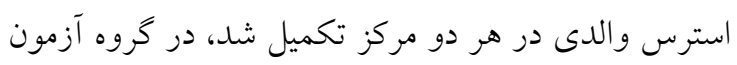
آموزش مهارتهاى زندگى طى يكى جلسه معارفه و ينج

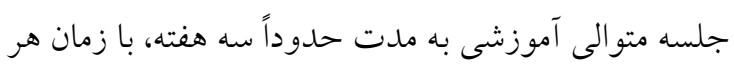

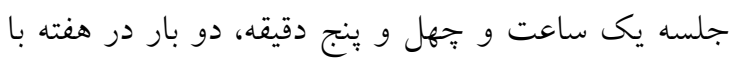

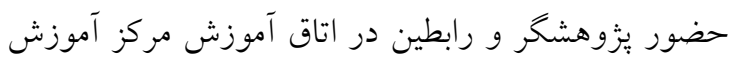
بهورزى در شبكه بهداشت و درمان شهرستان ابهر بركزار

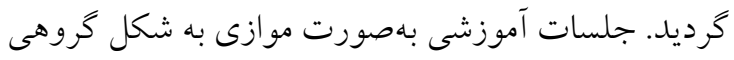

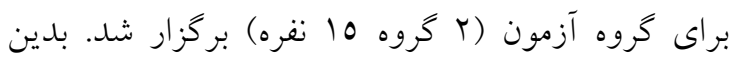
صورت كه در روزهاى يكشنبه و سهشنبه هر هفته براى دو كروه مختلف و در ساعتهاى مجزا جلسات بركزار شد.
كزارشدهى ا ست كه ميزان ا سترس را در ابعاد آ شفتخى

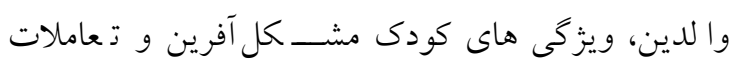

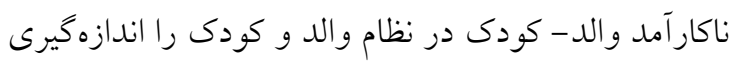

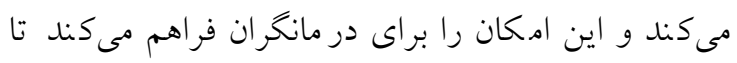

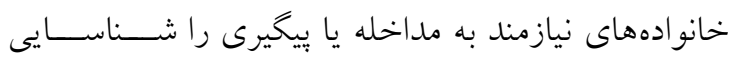

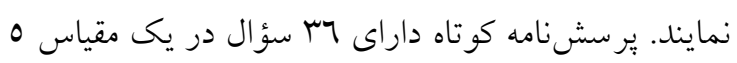
درجهاى است كه داراى سب سؤال از كاملاً موافقم تا كاملاً

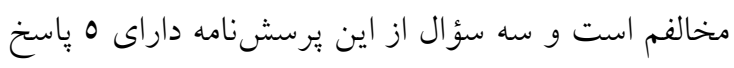

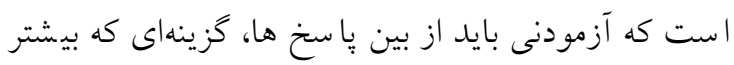

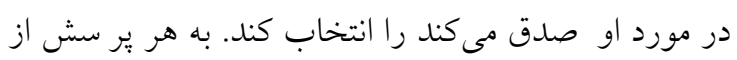

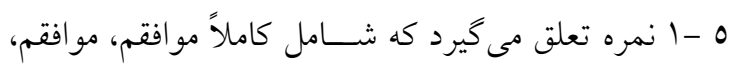

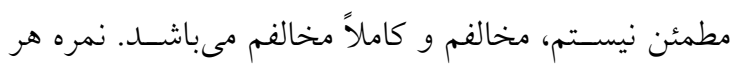
زير مقياس حاصل جمع نمرههاى داده شده است و نمره كل حاصل جمع نمره سه زير مقياس است. به اين ترتيب

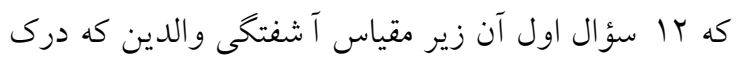

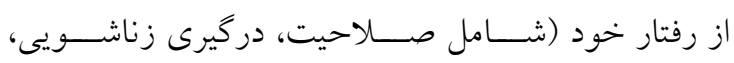

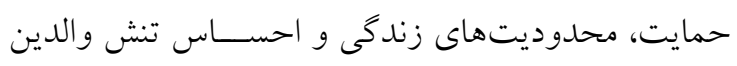

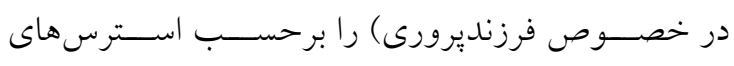

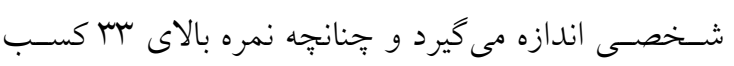

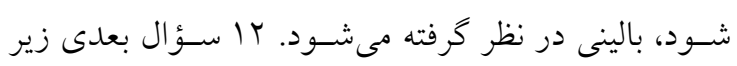

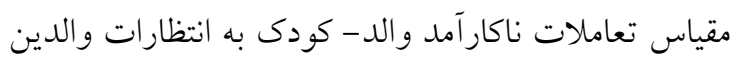

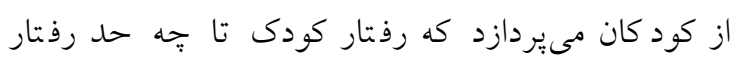

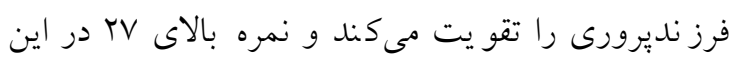

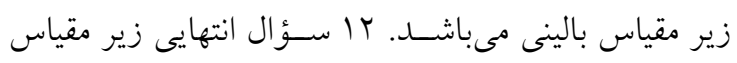

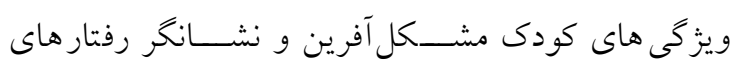

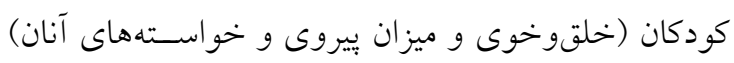

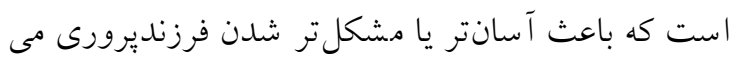

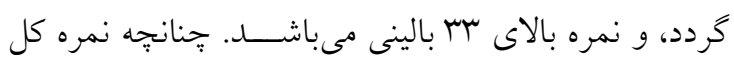

بالاى •9 باشد سطح بالاى استرس را نشان مىدهد (YV).

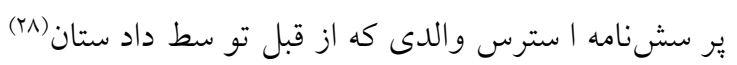
ترجمه شده بود و نسخه فارسى آن موجود بود، در مطالعه

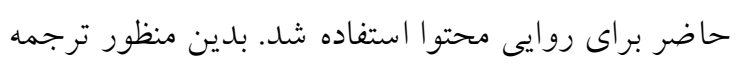
ير سشنامه جهت تعيين روايى به سه نفر از اساتيد محترم

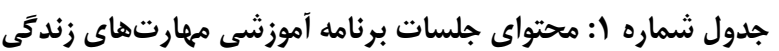




\begin{tabular}{|c|c|}
\hline معارفه و آشنايى اعضا با يكديخُ، كفتخو مقدماتى در مورد برنامه آموزشى، اهداف مداخله و اهميت موضوع & جلسه معارفه \\
\hline توضهارت خود آكاهى شامل آكاهى از نقاط قوت، آكاهى از نقاط ضعف، تصوير خود واقعبينانه، آكاهى از حقوق و مسئوليتها، & جلسه اول \\
\hline 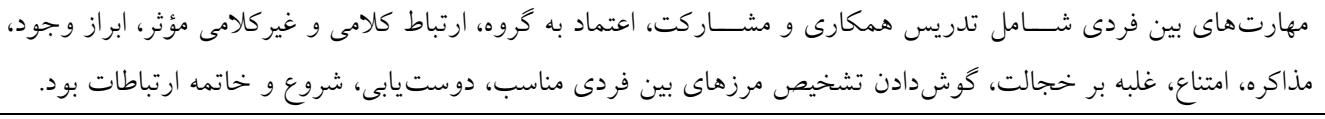 & جلسه دوم \\
\hline 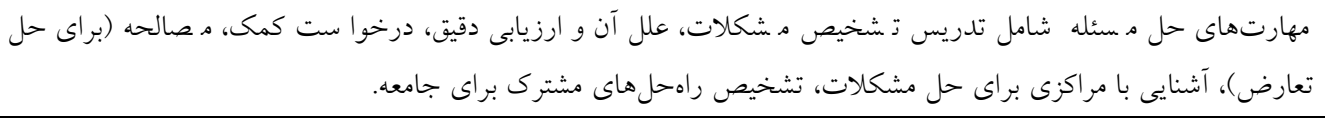 & جلسه سوم \\
\hline مقابله با ناكامى، خشاى مقابله با هيجانات شامل تدريس شناخت هيجانهاى خود و ديخران، ارتباط هيجانها با احساسات، تفكر و رفتار، & جلسه جهارم \\
\hline 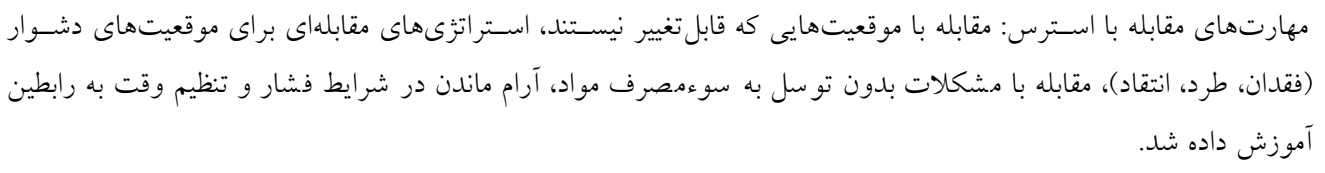 & جلسه ينجم \\
\hline دَ'.ارى آزمون ن & \\
\hline
\end{tabular}

آنها خواسته مى شد كه به تمرين و تكرار اين مهارتها در

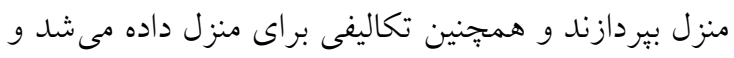

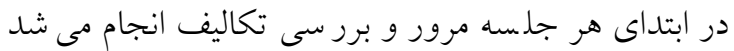
و يا توسـط داوطلبان به صسورت عملى انجام مى شــــ. به فيه

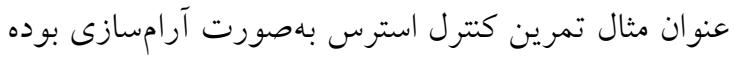
كه به صورت عملى توسط شركت كنند كان انجام مى شد.

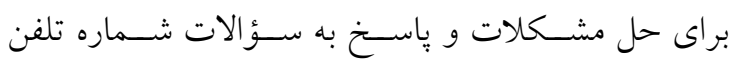

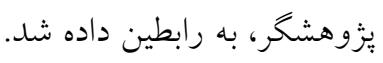

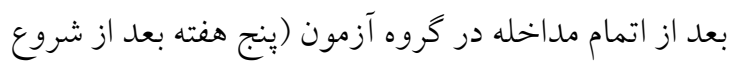

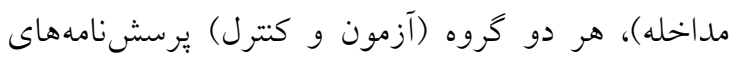

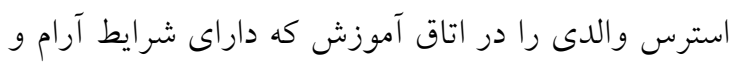
بدون استرس بود تكميل كرده و به يُزوهشكر تحويل دادند

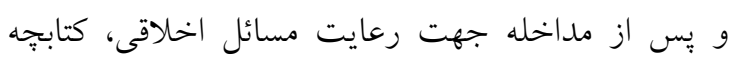
آموزشى در اختيار كروه كنترل نيز قرار كرفت.

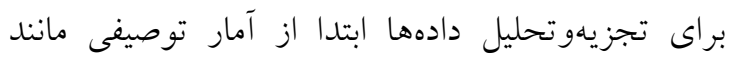

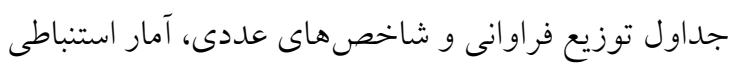

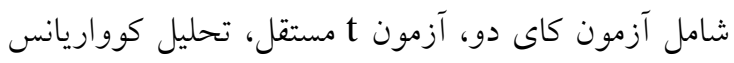
و آزمون من ويتنى استفاده شد و يرسشنامهها در سطح

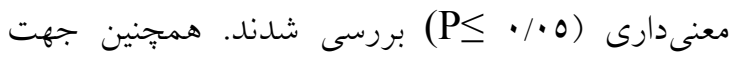

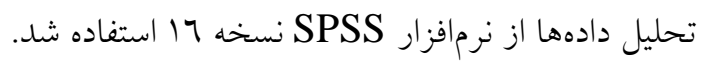

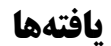

به منظور رعايت ملاحظات اخلاقى، پِ از كسب اجازه از كميته اخلاق دانشكاه علوم يزشكى و خدمات بهداشتى درمانى ايران (IR.iums.REC.1397.1165)، معرفى دمينه نامه از رياست دانشكده برستارى و مامايى دانشخاه علوم يزشكى ايران جهت انجام يُزوهش در مركز بهداشت

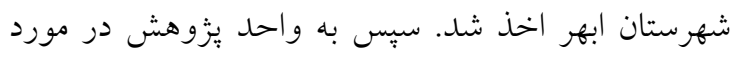

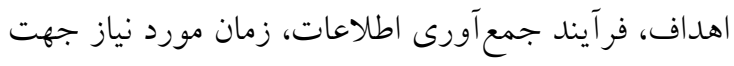

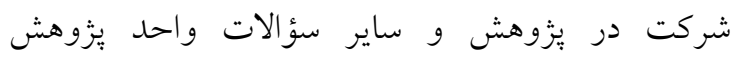

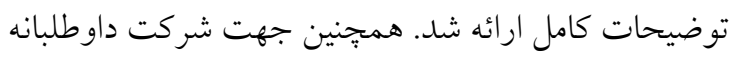
رابطين سلامت در ئزوهش، در مورد محرمانه بودن

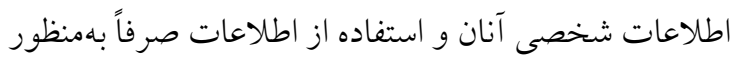
انجام يزووهش و عدم تحميل هيج گونه بار مالى براى آنها

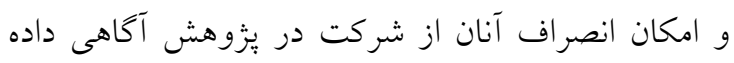

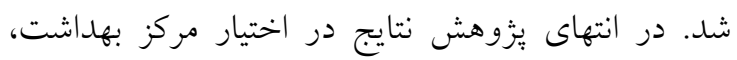

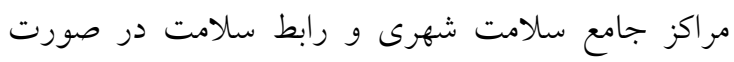

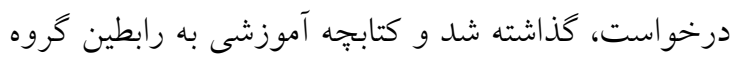
كنترل تحويل و يرسش و پِاسخ در مورد كتابجه بر گزار شد.

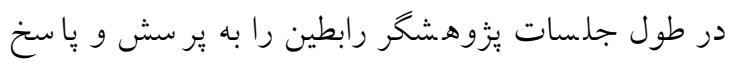

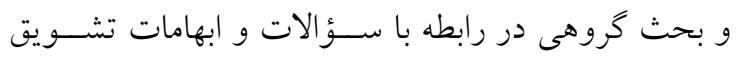

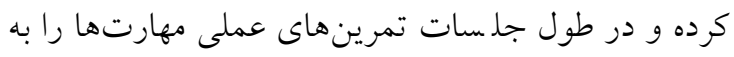
صورت ايفاى نقش در كلاس تمرين كردند و در بايان هر

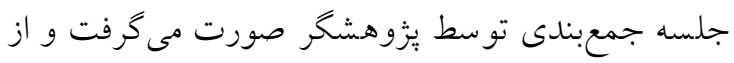


رابط سلامت با يك فرزند و در كروه آزمون بيشترين

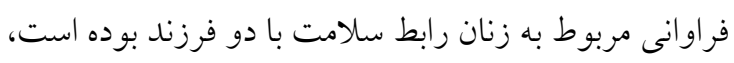

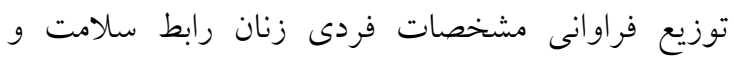

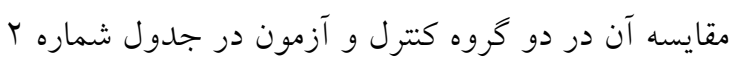
آمده است.
نتايج نشان داد بيش از نيمى از زنان رابط سلامت در رده سنى •r-rq سال قرار داشته و از نظر تحصيلات داراى

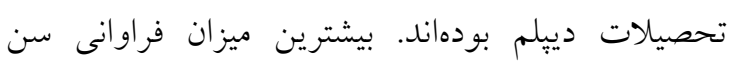

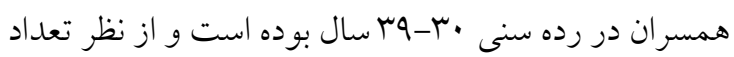
فرزندان در گروه كتترل بيشترين فراوانى مربوط به زنان بنان

جدول شماره r: توزيع فراوانى مشخصات فردى زنان رابط سلامت و مقايسه آن در دو تروه كنترل و آزمون

\begin{tabular}{|c|c|c|c|}
\hline نتايج آزمون تى مستقل & 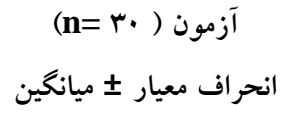 & 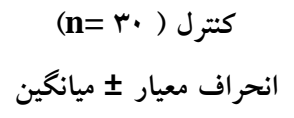 & متغير \\
\hline $\begin{array}{c}\mathrm{t}=\cdot / \cdot \quad \mathrm{df}=01 \\
\mathrm{P}>\cdot / 99\end{array}$ & $r / 77 \pm 0 / 0 Y$ & $\mu / \pi T \pm T / 1$ & سن (سال) \\
\hline $\begin{array}{c}\mathrm{t}=\cdot / \wedge 0 \wedge \quad \mathrm{df}=0 \wedge \\
\mathrm{p}=\cdot / \mu \mathrm{q}\end{array}$ & $r q / \cdots \pm v / 07$ & $\mathrm{rV} / 0 \pm 0 / \mathrm{AV}$ & سن همسر (سال) \\
\hline $\begin{array}{c}t=1 / 7 \varepsilon \wedge \quad d f=0 \wedge \\
p=\cdot / 1 \cdot 0\end{array}$ & $1 / \cdot \pm \wedge T / V V$ & $1 / 07 \pm \cdot / 7 r$ & تعداد فرزندان (نفر) \\
\hline $\begin{array}{c}\mathrm{t}=\cdot / \wedge / \varepsilon \quad \mathrm{df}=0 \wedge \\
\mathrm{p}=\cdot / / 19\end{array}$ & q/Ar $\pm 0 / V \varepsilon$ & $1 / 07 \pm 7 / 79$ & 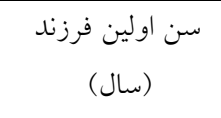 \\
\hline $\begin{array}{c}\mathrm{t}=\cdot / \cdot \mathrm{rr} \quad \mathrm{df}=01 \\
\mathrm{p}=\cdot / 991\end{array}$ & $7 / 20 \pm 0 / 7 V$ & $T / 2 Y \pm\{/ 07$ & 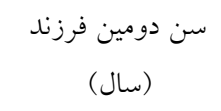 \\
\hline $\begin{array}{c}\mathrm{t}=\cdot / \mu / r \quad \mathrm{df}=01 \\
\mathrm{p}=\cdot / \text { NOT }\end{array}$ & $\varepsilon / 7 \pm 1 / 7 r$ & $\varepsilon / \varepsilon \neg \pm 1 / \tau V$ & سن فرزند موردنظر \\
\hline
\end{tabular}

از نظر شغل همسر زنان رابط سلامت بيشترين فراوانى

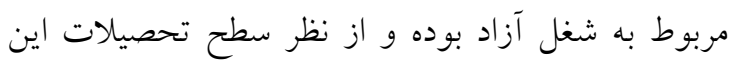

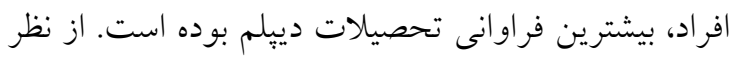

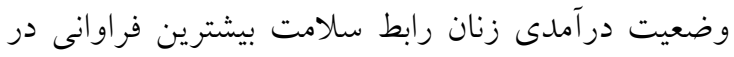

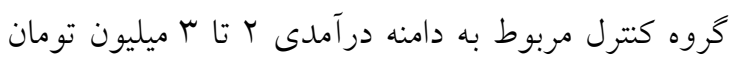

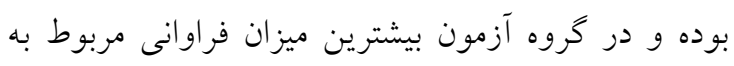

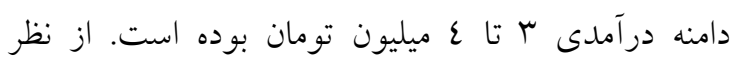

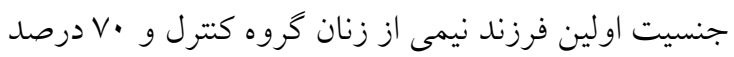
از زنان گروه آزمون دختر بودهاند.
طبق نتايج جداول شماره r و گ، دو گروه كنترل و آزمون

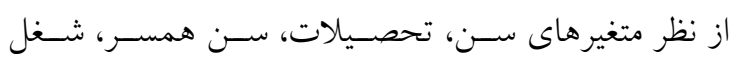

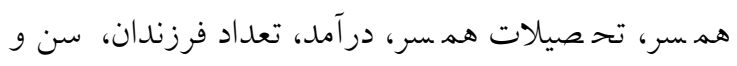

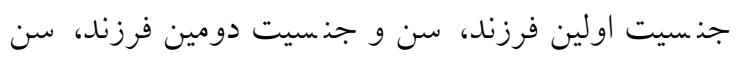
فرزند مورد نظر، مدت همكارى اختلاف معنى دار آمارى

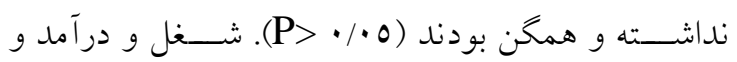

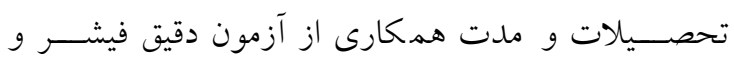
جنسيت فرزندان از آزمون كاى دو استفاده شد. 


\begin{tabular}{|c|c|c|c|c|c|c|}
\hline \multirow[t]{2}{*}{ نتايج آزمون دقيق فيشر و كاى دو } & \multicolumn{2}{|c|}{ آزمون (•r= (n) } & \multicolumn{2}{|c|}{ كنترل (n=r. } & \multirow[b]{2}{*}{ كروه } & \multirow[t]{2}{*}{ متغير } \\
\hline & درصد & فراوانى & درصد & فراوانى & & \\
\hline \multirow{3}{*}{$\mathrm{p}=\cdot / 1$} & $17 / \mathrm{V}$ & 0 & $17 / V$ & 0 & زير دييلم & \\
\hline & r/r & 19 & 0. & 10 & دييلم & تحصيلات \\
\hline & $r$. & 7 & $\mu r / \varepsilon$ & 1. & دانشخاهى & \\
\hline \multirow{7}{*}{$\mathrm{P}=\cdot / r\urcorner \Lambda$} & $77 / \mathrm{V}$ & $r$. & or/r & 17 & آزاد & \\
\hline & r. & 7 & $r$. & 7 & كارگر & \\
\hline & 1. & r & $r T / V$ & $\wedge$ & كارمند & شغل همسر \\
\hline & r/ & 1 & . & . & بيكار & \\
\hline & rev & 11 & r. & 7 & زير ديبلم & \\
\hline & rre & 17 & $\varepsilon r / \mu$ & ir & ديبلم & \\
\hline & 1. & r & $\mathrm{ru} / \mathrm{v}$ & 11 & دانشخاهى & \\
\hline \multirow{4}{*}{$P=\cdot / 9 \cdot 7$} & $\mu \mu / \mu$ & v & $r$. & 7 & كمتر از دو ميليون & \\
\hline & $r$. & 9 & $\varepsilon$. & ir & r تا ب ميليون & درآمد \\
\hline & $\mu r / \varepsilon$ & 1. & $r T / V$ & $\wedge$ & r تا ع ميليون & \\
\hline & $1 \pi / 4$ & $\varepsilon$ & $1 \% / \mu$ & $\varepsilon$ & ع و بالاتر & \\
\hline$X^{2}=r / 0$ & $r$. & 9 & 0. & 10 & 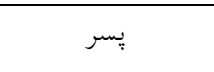 & جنسيت اولين \\
\hline $\mathrm{p}=\cdot / 1 / \varepsilon \quad \mathrm{df}=1$ & $v \cdot$ & rI & 0. & 10 & دختر & فرزند \\
\hline \multirow{2}{*}{$\begin{array}{c}\chi^{2}=r / \varepsilon \varepsilon r \\
d f=r\end{array}$} & $\mu \mu$ & 1. & or/r & 17 & 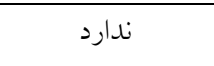 & جنسيت دومين \\
\hline & r & 1. & $r \mu / \mu$ & v & 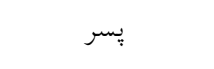 & فرزند \\
\hline $\mathrm{p}=\cdot / / 90$ & $\mu \mu$ & 1. & $r \mu / r$ & v & دختر & \\
\hline \multirow[t]{2}{*}{$\mathrm{p}=\cdot / T r V$} & . & · & 1. & r & يكسال & مدت همكارى \\
\hline & $1 \cdots$ & $r$. & 9. & TV & بالاى يكسال & \\
\hline
\end{tabular}

جدول شماره ع: مقايسه استرس والدى زنان رابط سلامت در دو تَروه كنترل و آزمون در مراحل يبش آزمون - يس آزمون

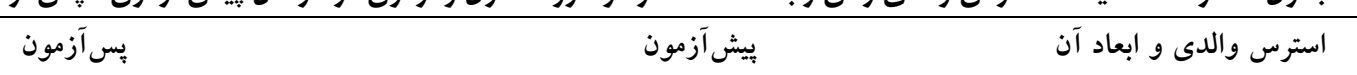

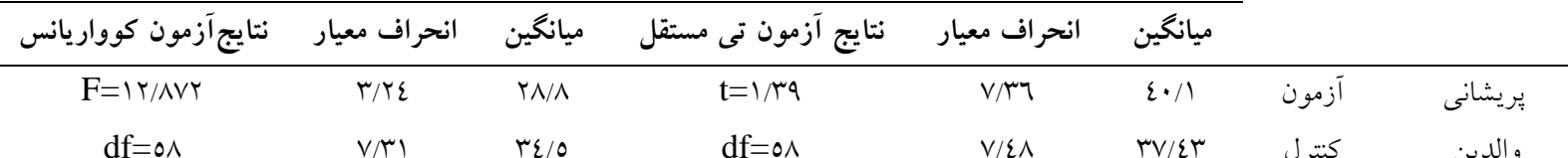

\begin{tabular}{|c|c|c|c|c|c|c|c|}
\hline $\mathrm{p}=\cdot / \cdot \cdot 1$ & & & $\mathrm{p}=\cdot / / \mathrm{V}$ & & & & \\
\hline $\mathrm{F}=\cdot / \varepsilon{ }^{\mu} \wedge$ & $r / M$ & TV/ar & $\mathrm{t}=\cdot / \mu r 1$ & $V / .9$ & $\pi / / 0$ & آزمون & تعامل اختلال \\
\hline $\mathrm{df}=0 \wedge$ & $T / 2 V$ & $r N / 9$ & $d f=0 \wedge$ & $7 / 11$ & $r \varepsilon / .7$ & كتترل & عملكرد والدين \\
\hline $\mathrm{p}=\cdot \cdot / 011$ & & & $\mathrm{p}=\cdot / \mathrm{V} \varepsilon \mathrm{r}$ & & & & - كودى \\
\hline $\mathrm{F}=\cdot / 091$ & $r / 70$ & $\mu / 1$ & $\mathrm{t}=r / T q r$ & $0 / N V$ & $\varepsilon \cdot / V$ & آزمون & \\
\hline $\mathrm{df}=0 \wedge$ & $\varepsilon / \mu\urcorner$ & $r \eta / r$ & $\mathrm{df}=0 \wedge$ & $\varepsilon / \pi\}$ & rV/A & كتترل & كودى دشوار \\
\hline $\mathrm{p}=\cdot / \varepsilon \varepsilon r$ & & & $\mathrm{p}=\cdot / \cdot$ ro & & & & \\
\hline $\mathrm{F}=0 / r q r$ & $N / I V$ & 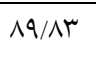 & $t=1 / r \cdot 0$ & $17 / \% 9$ & $11 \varepsilon / r$ & آزمون & \\
\hline $\mathrm{df}=\Delta \wedge$ & IE/Or & $9 \vee / 7$ & $\mathrm{df}=\Delta \wedge$ & $14 / 1$ & $1.9 / r$ & كنترل & استرس والدى \\
\hline $\mathrm{p}=\cdot / \cdot r \varepsilon$ & & & $\mathrm{p}=\cdot / / 9 \mathrm{~V}$ & & & & \\
\hline
\end{tabular}


همجنين ميانخين نمره اسـترس والدى و بعلد بريشـانى

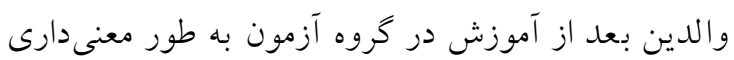

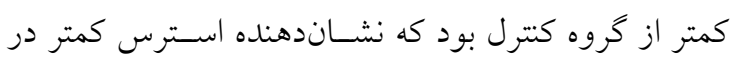

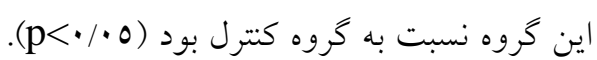

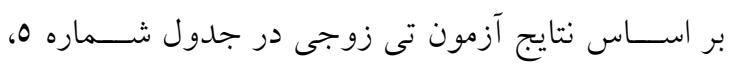

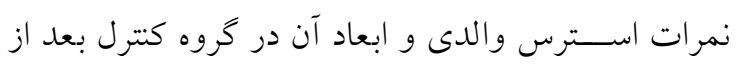

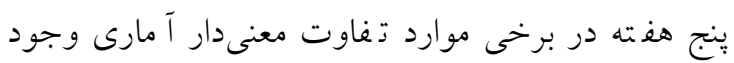
داشته است ولى نمرات استرس والدى و ابعاد آن در خروه

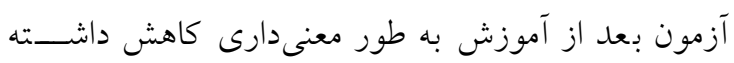

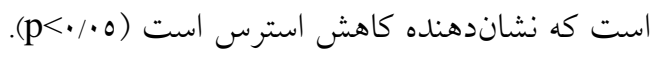

جدول شماره 0: مقايسه درونَّروهى استرس والدى زنان رابط سلامت در مراحل يِيشآزمون - يس آزمون

\begin{tabular}{|c|c|c|c|c|c|c|c|c|c|c|}
\hline \multirow{3}{*}{ زآزمون تى } & \multicolumn{4}{|c|}{ كروه آزمون } & \multirow{3}{*}{ تنى نتايج } & \multicolumn{4}{|c|}{ كروه كترل } & \multirow{3}{*}{ و استرس والدى آن } \\
\hline & \multicolumn{2}{|c|}{ بِ آزمون } & \multicolumn{2}{|c|}{ بيش آزمون } & & \multicolumn{2}{|c|}{ بِ آزمون } & \multicolumn{2}{|c|}{ بيش آزمون } & \\
\hline & انحر اف معيار & ميانكين & انحر افمعيار & ميانكين & & انحر افمعيار & ميانكين & انحرافمعيار & ميانكين & \\
\hline$t=1 \cdot / r \wedge \varepsilon$ & & & & & $t=1 / \cdot M$ & & & & & بريشانى \\
\hline$d f=r a$ & $r / r \varepsilon$ & TN/A & $v / \pi$ & $\varepsilon \cdot / 1$ & $\mathrm{df}=r q$ & $V / \mu l$ & $r \varepsilon / 0$ & $V / \Sigma \Lambda$ & $r V / \varepsilon r$ & و الدين \\
\hline $\mathrm{p}<\cdot / \cdot .1$ & & & & & $\mathrm{p}=\cdot / T \wedge T$ & & & & & \\
\hline $\mathrm{t}=\mathrm{V} / \mu \cdot \varepsilon$ & & & & & $\mathrm{t}=r / \mathrm{TVV}$ & & & & & تعامل اختلال \\
\hline$d f=r a$ & $r / M$ & TV/qT & $V / .9$ & $\mu_{T} / 0$ & $\mathrm{df}=r q$ & $T / 2 V$ & $r N / q$ & $7 / 1$ & $r \varepsilon / .7$ & عملكردو الدين - \\
\hline $\mathrm{p}<\cdot / \cdot .1$ & & & & & $\mathrm{p}=\cdot / \cdot 1 \mathrm{r}$ & & & & & كودى \\
\hline$t=11 / 791$ & & & & & $\mathrm{t}=r / Y O \Lambda$ & & & & & \\
\hline $\mathrm{df}=r q$ & $r / 70$ & $\pi / 1$ & $0, \pi v$ & $\varepsilon \cdot / v$ & $\mathrm{df}=r q$ & $\varepsilon / \pi\urcorner$ & $r \bar{r} / r$ & $\varepsilon / \pi\urcorner$ & $r V / \Lambda$ & كودى دشوار \\
\hline $\mathrm{p}<\cdot / \cdot .1$ & & & & & $\mathrm{p}=\cdot / \cdot r \mathrm{r}$ & & & & & \\
\hline $\mathrm{t}=I Y / 2 \Psi T$ & & & & & $\mathrm{t}=r / \varepsilon \cdot 1$ & & & & & \\
\hline$d f=r q$ & $N / I V$ & $\wedge 9 / \wedge r$ & $17 / r 9$ & $11 \varepsilon / r$ & $\mathrm{df}=r q$ & $1 \varepsilon / 0 r$ & $9 \vee / 7$ & $1 \% / 1$ & $1.9 / \%$ & استرس والدى \\
\hline $\mathrm{p}<\cdot / \cdot \cdot 1$ & & & & & $\mathrm{p}=\cdot / \cdot r \mu$ & & & & & \\
\hline
\end{tabular}

به طور معنى دارى بيشتر از گروه كنترل است به طورى كه بررسى بر روى تغييرات نمرات در استرس والدى و ابعاد

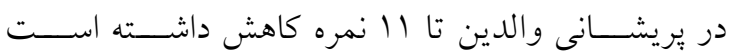

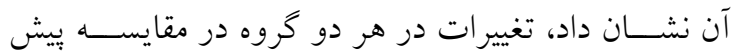

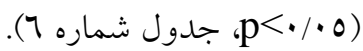
آزمون و يّ آزمون منفى بوده كه ذشاندهنده كاهش نمره

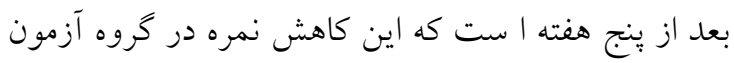
جدول شماره ا: مقايسه تغييرات استرس والدى و ابعاد آن در زنان رابط سلامت در تروه كنترل و وآزمون

\begin{tabular}{|c|c|c|c|c|c|}
\hline \multirow{2}{*}{ نتيجه آزمون من } & \multicolumn{2}{|c|}{ 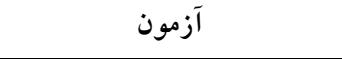 } & \multicolumn{2}{|c|}{ 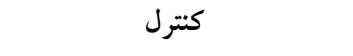 } & \multirow[t]{2}{*}{ تغييرات استرس والدى و ابعاد آن } \\
\hline & انحراف معيار & 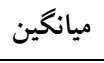 & انحر اف معيار & 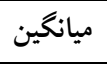 & \\
\hline $\mathrm{P}=\cdot / \cdot \varepsilon 9$ & $0 / 97$ & $-11 / \pi$ & $1 \varepsilon / N 7$ & $-r / 9 r$ & يريشانى والدين \\
\hline$P=\cdot / \wedge 09$ & $\varepsilon / / V$ & $-0 / 07$ & $1 \cdot 10 \mathrm{~V}$ & $-0 / 17$ & تعامل اختلال عملكرد والدين - كودى \\
\hline $\mathrm{P}=\cdot / \cdot 17$ & $r / 00$ & $-V / 7$ & $\Lambda / N r$ & $-r / 7$ & كودى دشوار \\
\hline $\mathrm{P}=\cdot / \cdot \mathrm{rO}_{0}$ & $1 \cdot / \mathrm{VV}$ & $-\Upsilon \varepsilon / \varepsilon\rceil$ & $r 7 / 79$ & $-11 / \mathrm{V}$ & استرس والدى \\
\hline
\end{tabular}


والدگرى مادران و افزايش بذيرش و الدينى كودكان دبستانى

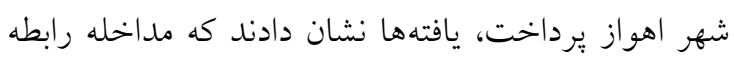

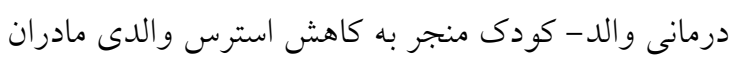

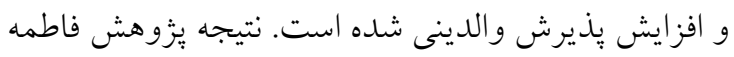

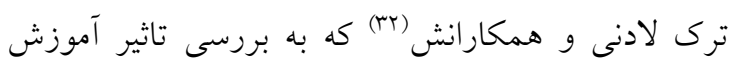

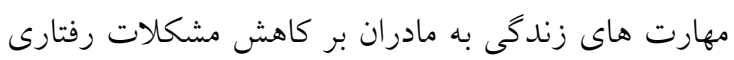

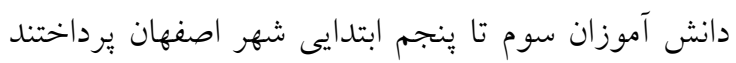

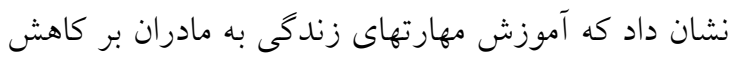

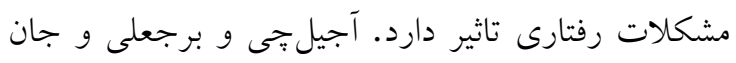

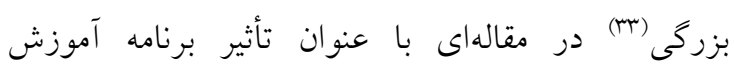

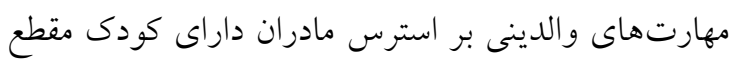

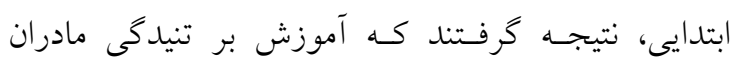

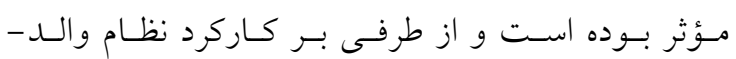

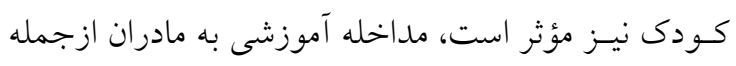
كارايى ترين شيوه بيشـيرى و كنترل استرس والدى است است.

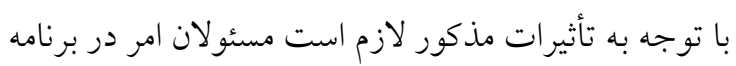

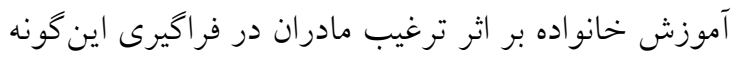

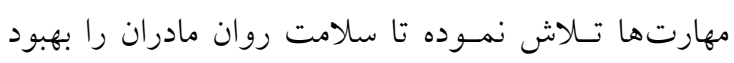

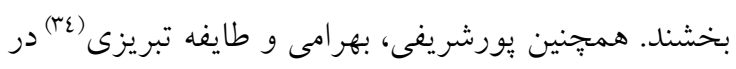

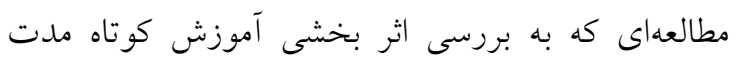

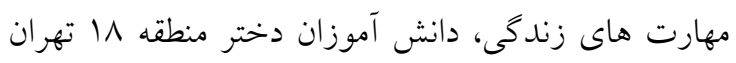

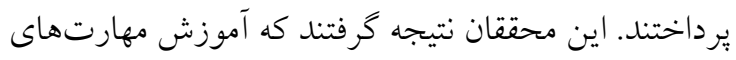

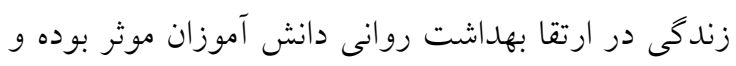

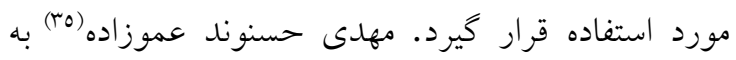

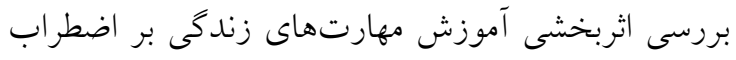

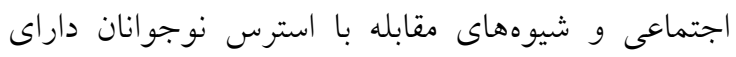

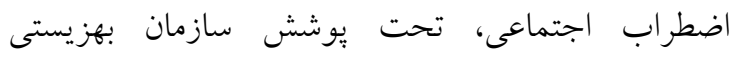

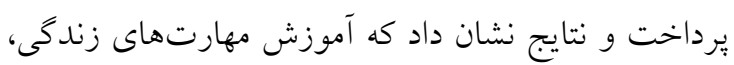
موجب كاهش معنى دار نمرههاى اضطراب اجتماعى، شيوه مقابله هيجان مدار و شيوه مقابله اجتناب مدار و نيز افزايش معنى دار نمرههاى شيوه مقابله مسأله مدار گروه در مديريت استرس كرديد. در تحقيق زهرا رحيمى و همكاران(r)(به به بررسى تأثير برنامه مهارت زندگى در شادكامى و تاب

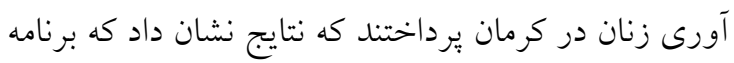

بحث و نتيجه كيرى

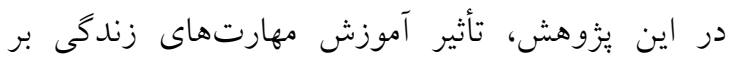

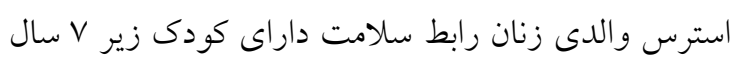

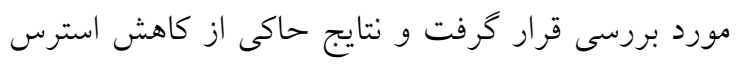

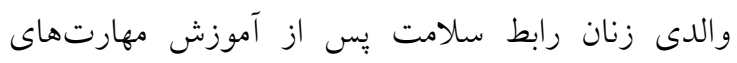

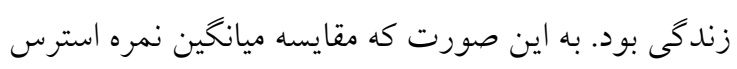

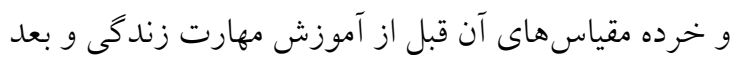

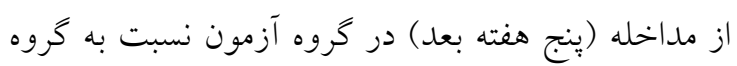

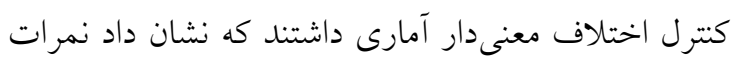

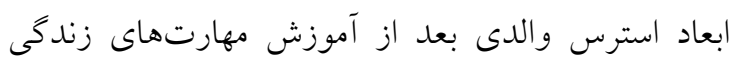

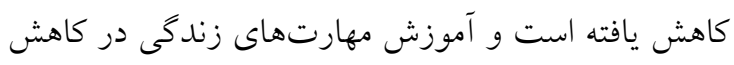

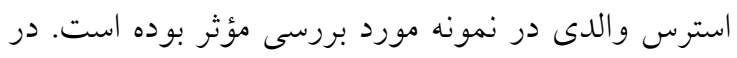

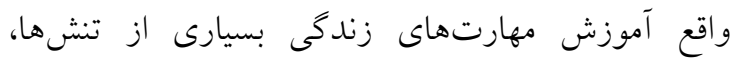
اضطر ابها و كاركردهاى ناقص اجتماعى را كاهش مىدهد

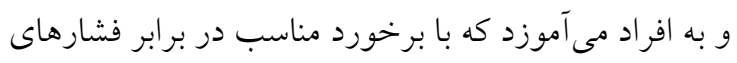

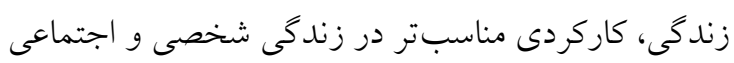

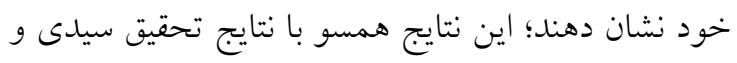

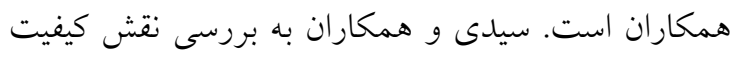

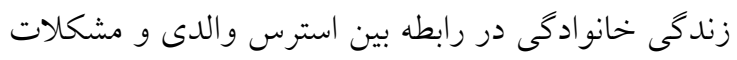

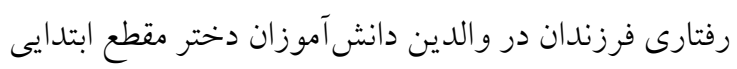

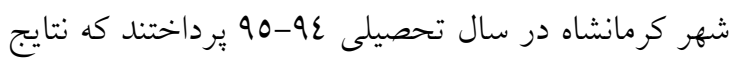

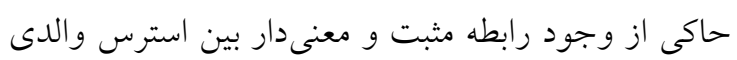

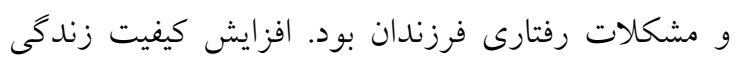

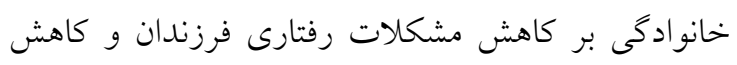
استرس والدين اثر داشت. همجنين همسو با تحقيقات

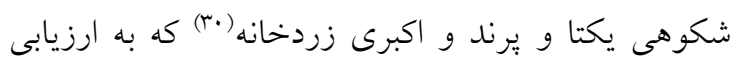

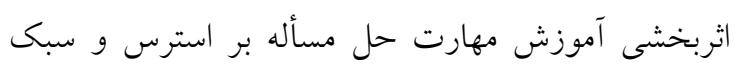

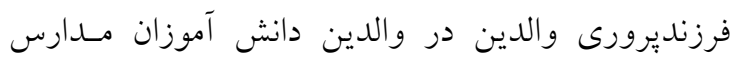

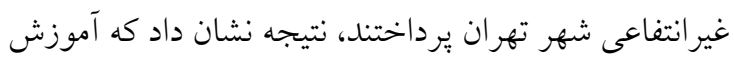

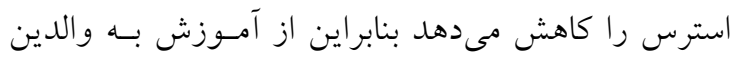

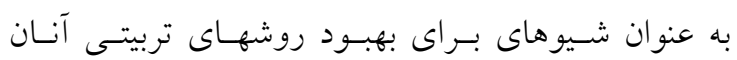

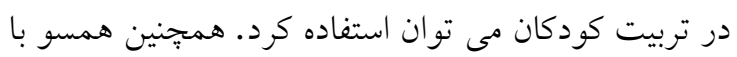

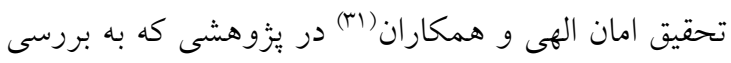

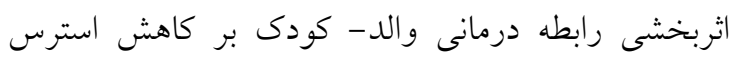


داشـــ؛ بنابر اين با به كاركيرى برنامه آموزش مهارتهاى

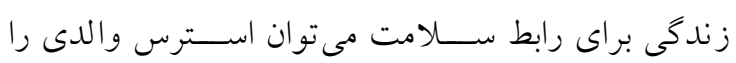
كاهش داد. اما نكتهاى كه بايد مدنظر قرار كيرد اين اسـت

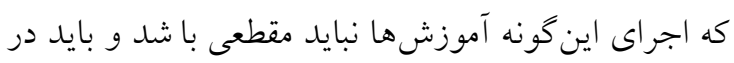

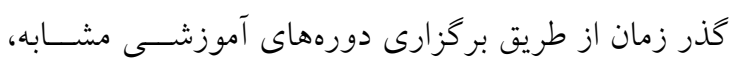

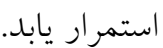

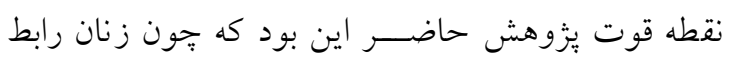

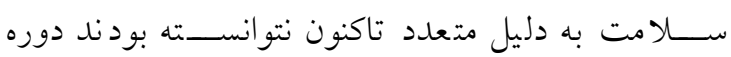

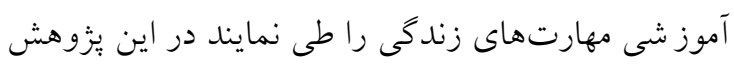

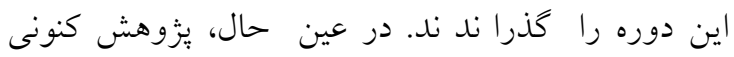
محدوديتهايى نيز داشت. از جمله اينكه مشاركت كنند كان در اين مطالعه، زنان رابط سلامت داراى كودى زير V سال

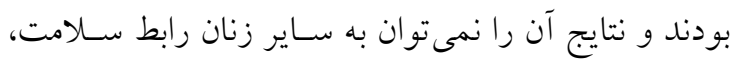

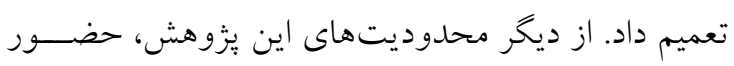

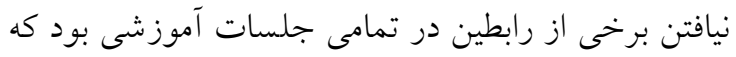

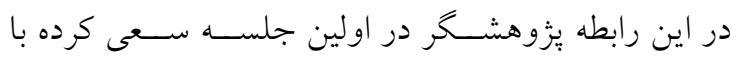

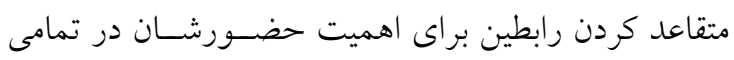
جلســات آموزشــى، اين محدوديت را در طول مرل مداخله

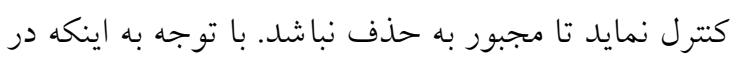

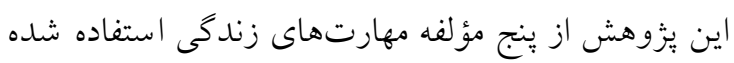

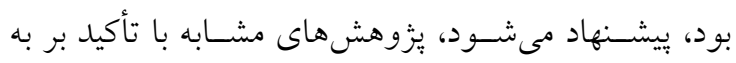

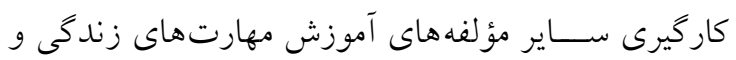

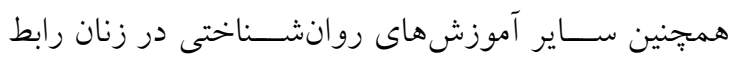

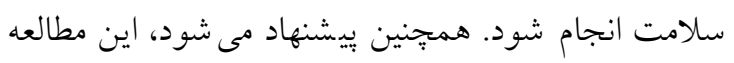
در ساير شهرها و استانهاى كشور به شكل مقائسهاى

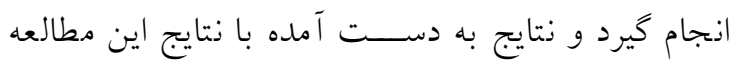

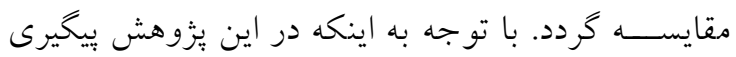

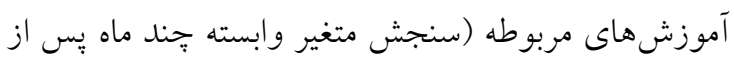

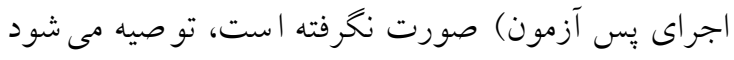

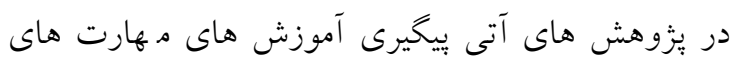

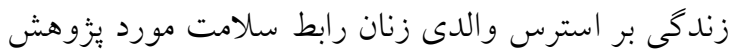

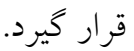

مهارت زندگى مؤثر است. حسن غريبى و همكاران (rV) به

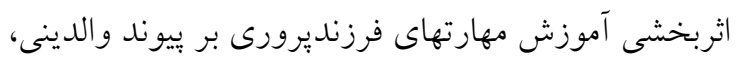

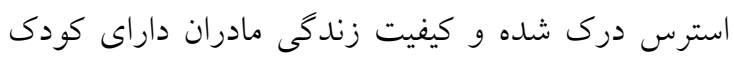

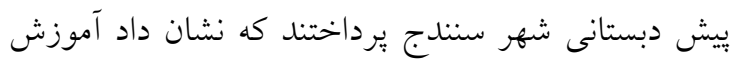

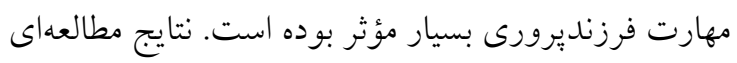
كه توسط خوشاب(r)" و همكاران در راستاى تعيين تأثير مديريت استرس والدى صورت كرفت نشان داد ميزان استرس والدى اين كروه از نمونهها در اثر آموزش

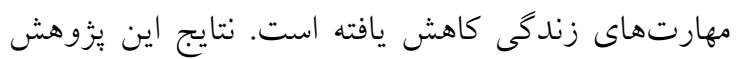
نيز با نتايج به دست آمده در مطالعه حاضر همراستا است. در مطالعه ديخرى كه رضايى، غضنفرى و رضائيان("ه)

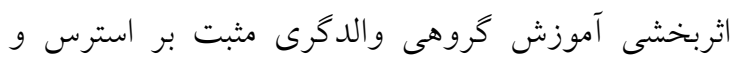

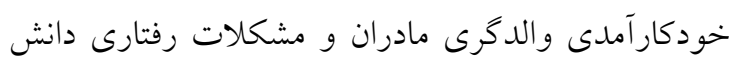

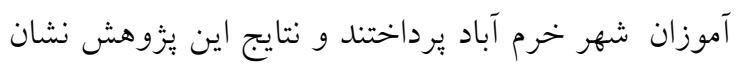

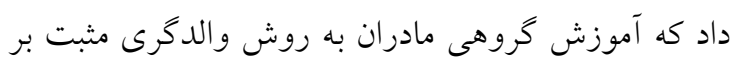

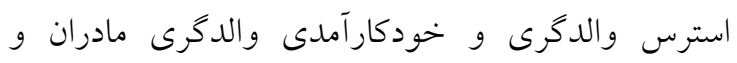

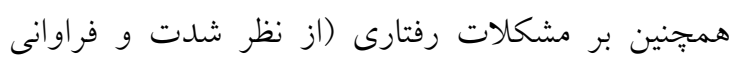

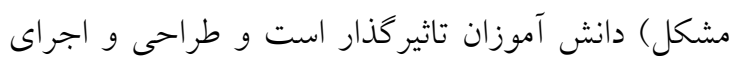
جلسات آموزش براى والدين ييشنهاد مى شود. كه با نتايج مطالعه حاضر هم سو مىباشد.

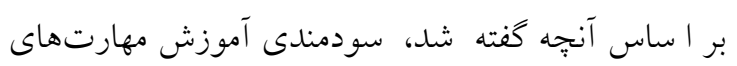

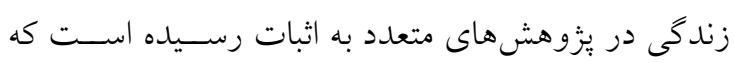

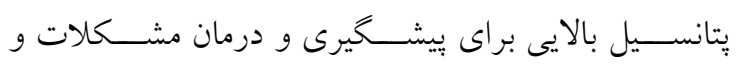

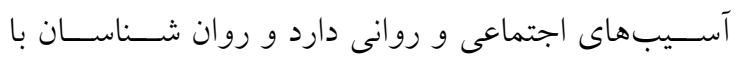

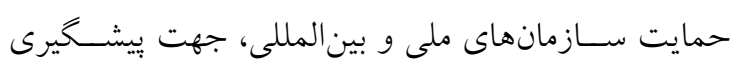

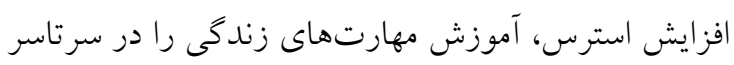

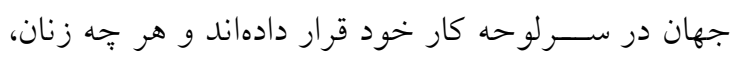
تسـلط بيشـترى بر مهارت كترل اسـترس داثـته باشـنـا،

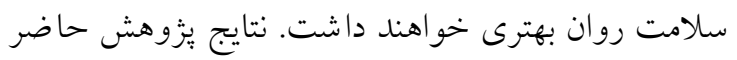

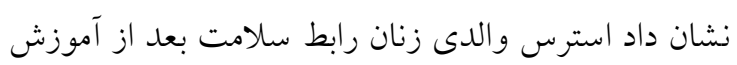

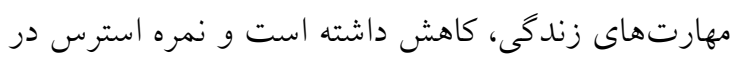
هر سه حوزه استرس والدى شامل يريشانى والدين، تعامل

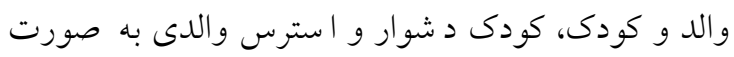

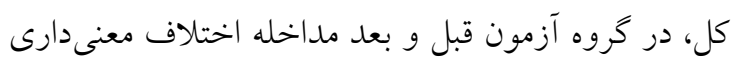




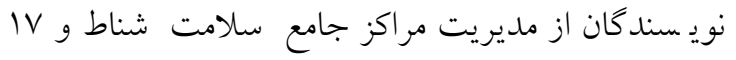

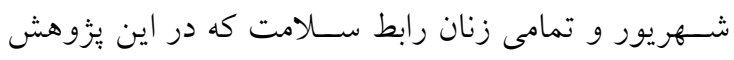

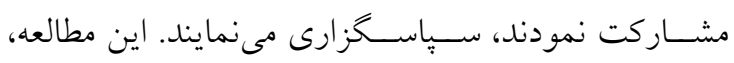

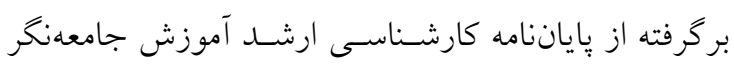

$$
\begin{aligned}
& \text { در نظام سلامت در دانشخاه علوم يزشكى ايران است. }
\end{aligned}
$$

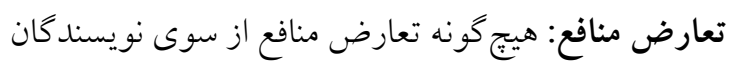
كزارش نشده است.

\section{References}

1. Shokoohi-Yekta M, Parand A, Akbari Zardkhaneh S. Effectiveness of teaching problem-solving skills 1 stress and parenting style. Knowledge \& Research in Applied Psychology. 2014;15(3):4553. [Persian]

1. 2 Kakavandi KH, Shojaee S. The Effectiveness of Life Skills Training on the Mother-Child Relationship in Mothers of Children with Hearing Problems. Journal of Family Research. 2016;12(3):483-500. [Persian]

2. Harmeyer E, Ispa JM, Palermo F, Carlo G. Predicting self-regulation and vocabulary and academic skills at kindergarten entry: The roles of maternal parenting stress and mother-child closeness. Early Childhood Research Quarterly. 2016;37:153-64.

3. Li ST, Chiu NC, Kuo YT, Shen EY, Tsai PC, Ho CS, Wu WH, Chen JC, Wang CY, Wang HS, Lin KL. Parenting stress in parents of children with refractory epilepsy before and after vagus nerve stimulation implantation. Pediat Neonatol. 2017;58(6):516-22.

4. Seydi M. The effect of the quality of family and family life satisfaction in reducing anxiety and depression in children and moderating role of parenting stress. Journal of Counseling Research. 2018;17(66):178-200. [Persian]

5. Anthony LG, Anthony BJ, Glanville DN, Naiman DQ, Waanders C, Shaffer S. The relationships between parenting stress, parenting behaviour and preschoolers' social competence and behaviour problems in the classroom. Infant and Child Development: An International Journal of Research and Practice. 2005;14(2):133-54.

6. Lin KY, Burgard SA. Working, parenting and work-home spillover: Gender differences in the work-home interface across the life course. Adv Life Course Res. 2018;35:24-36.

7. Reynolds SA, Fernald LC, Behrman JR. Mothers' labor market choices and child development outcomes in Chile. SSM-population health. 2017;3:756-66.

8. Nemati I, Zadehmohammadi A, Fathabadi J. Parenting Stress and Interactive Effect of Family Life Cycle Stages of Employed and Unemployed Women in Tehran. WOMAN \& STUDY OF FAMILY. 2015;8(29):7-22. [Persian]

9. Torkaman SO, Fathi SO. Study the effect of women's employment concerns over the quality of their lives. Quarterly Journal of Women and Society. 2017;7(28):13-26. [Persian]

10. Masti E, Fakhrayi S. The study of the relationship between women's employment and their social health in maragheh. Journal Of Sociology Studies. 2014 ;6(24):117-33. [Persian]

11. Yousefi A, Baratali M, Erfan A. The relationship between mental health, employment and having higher education among female students of Isfahan University of Medical Sciences. Iranian Journal of Medical Education. 2011;10(5):748-54. [Persian]

12. Zanjani HA, Baghiat IZ. The effect of employ mentand family life on satisfaction of the female teachers (Case study: The employed teachers in zone one, Karaj). Journal Of Specialized Social Science. 2014;10(39):13-31. [Persian]

13. Abidin RR. Parenting stress index-short form. Charlottesville, VA: Pediatric psychology press; 1990.

14. Gharibi H, Sheidai A, Rostami CH. The Effectiveness of Parenting Skills Training on Attachment, Perceived Stress and Quality of Life in Mothers of Preschool Children. Journal of Health and Care. 2017;18(4):292-305. [Persian] 
15. Moridi J, Askari M. The Effect of Training of Stress Management on life Quality and Mental Control of Mothers with Autism off Spring. International Journal of Current Research in Medical Sciences. 2016;2(7):40-9. [Persian]

16. Maguire-Jack K, Negash T. Parenting stress and child maltreatment: The buffering effect of neighborhood social service availability and accessibility. Children and Youth Services Review. 2016;60:27-33.

17. Cooper CE, Jonathans MC, Meadows SO. Family structure tarnation and maternal parenting stress. J Marriage Fam. 2009; 71(3), 558-74.

18. Coleman PK, Karraker KH. Parenting self-efficacy among mothers of school-age children: Conceptualization, measurement, and correlates. Family relations. 2000;49(1):13-24.

19. Gharibi H, Sheidai A, Rostami CH. The Effectiveness of Parenting Skills Training on Attachment, Perceived Stress and Quality of Life in Mothers of Preschool Children. Journal of Health and Care. 2017;18(4):292-305. [Persian]

20. Samari AA, LALIFAZ A. Effectiveness of life skills education on family stress and social acceptance. Journal Of Fundamentals Of Mental Health. 2005; 7 (25-26), 47-55. [Persian]

21. Irelan J, Vayzner M. Family Life Education. A Program of Lutheran Child and Family Services of Ilinois. 2005.

22. Östberg M, Hagekull B, Hagelin E. Stability and prediction of parenting stress. Infant and Child Development: An Int J Res Pract. 2007;16(2):207-23.

23. Hejazi M, Sobhi A, SadeghiJahan A. Efficacy of life skills training on reducing anxiety and depression in drug dependent subjects. J Adv Med Biomed Res. 2016;24(104):20-8. [Persian]

24. World Health Organization. Life skills education school handbook: prevention of noncommunicable diseases: approaches for schools. 2020.

25. Farrace D, Tommasi M, Casadio C, Verrotti A. Parenting stress evaluation and behavioral syndromes in a group of pediatric patients with epilepsy. Epilep Behav. 2013;29(1):222-7.

26. Fadaei Z, Dehghani M, Tahmasian K, Farhadei M. Investigating reliability, validity and factor structure of parenting stress-short form in mothers of 7-12 year-old children. Journal Of Research In Behavioural Sciences . 2010;8(2):81-91. [Persian]

27. Dadsetan P, Ahmadi Azghandi A, Hassanabadi HR. Parenting stress and general health: A research on the relation between parenting stress and general health among housewife-mothers and nursemothers with young children.Developmental Psychology (Journal OF Iranian Psychologists). 2006;2(7):171-84. [Persian]

28. Reitman D, Currier RO, Stickle TR. A critical evaluation of the Parenting Stress Index-Short Form (PSI-SF) in a head start population. J Clin Child Adoles Psychol. 2002;31(3):384-92.

29. Shokoohi-Yekta M, Parand A, Akbari Zardkhaneh S. Effectiveness of teaching problem-solving skills on parental stress and parenting style. Knowledge \& Research in Applied Psychology. 2014;15(3):45-53. [Persian]

30. Aman Elahi, A., and Shadfar, A., and Aslani, Kh.. Effects of Child-Parent Relationship Therapy on Maternal Parenting Stress and Parental Acceptance of Primary School Children. Quarterly Journal of Family and Research. 2019;15(4):103-20.

31. Tork LF, Malekpour M, Golparvar M. The effect of mothers life skills training on behavioral problems of students in third to fifth grade of elementary school in Isfahan City in the academic year 1386-1387. Knowledge and Research in Applied Psychology, 2008;10(37):65-82. [Persian]

32. Ajilchi B, Borjali A, Janbozorgi M. The impact of a parenting skills training program on stressed mothers and their children's self-esteem level. Procedia-Social and Behavioral Sciences. 2011;30:316-26.

33. Poursharifi H, Bahrami EH, Tayefeh TR. Efficacy of short-term instruction of life skills. Contemporary Psychology. 2006;1(1):40-7. [Persian]

34. Hassanvand Amouzadeh M, Heydari E. The role of goal orientation learning and goal orientation performance on Prediction of self-regulated learning amongst welfare organization client students. Rooyesh-e-Ravanshenasi Journal (RRJ). 2019;7(12):71-85.

35. Eslahi F, Abolmaali AK, Asgharnejad AA, Khalatbari J. An Investigation of Mindfulness-Based Metaphors in the Poems of Rumi. Consulting Research (News and Consulting Research). 2020;19(74):62-90. [Persian] 
36. Gharibi H, Sheidai A, Rostami CH. The Effectiveness of Parenting Skills Training on Attachment, Perceived Stress and Quality of Life in Mothers of Preschool Children. Journal of Health and Care. 2017;18(4):292-305. [Persian]

37. Khooshab E, Jahanbin I, Ghadakpour S, Keshavarzi S. Managing parenting stress through life skills training: A supportive intervention for mothers with visually impaired children. Int J Commun Based Nurs Midwif. 2016;4(3):265. [Persian]

38. Rezaei F, Ghazanfari F, Purrezaian M. The Effectiveness of Positive Parenting Program (Triple-P) in Parental stress and Self Efficacy of mothers and behavioral problems of students with educable mental retardation. Journal of Torbat Heydariyeh University of Medical Sciences. 2017;5(1):7-16. [Persian] 